Examining Gender Differences in Predictors of Financial Satisfaction: Evidence from Taiwan

Derek T. Tharp \& Elizabeth J. Parks-Stamm

University of Southern Maine

September 21, 2020 


\begin{abstract}
Using an integrative model of top-down and bottom-up influences on financial satisfaction, this study examines gender differences in the predictors of financial satisfaction in Taiwan. Using the 2016 wave of the Panel Study of Family Dynamics (PSFD), gender differences in the extent to which top-down (trait positive and negative affect) and bottom-up (demographic, financial, and social support) factors predicted financial satisfaction were explored within three Taiwanese social contexts: all adults $(n=3,593)$, working adults $(n=2,713)$, and married working adults $(n=1,306)$. Varied gender differences were observed across all three social contexts. In particular, income (more strongly associated among men than women), education (more strongly associated among women than men), and trait negative affect (more strongly associated among women than men) tended to predict financial satisfaction differently by gender. Trait positive affect predicted financial satisfaction regardless of gender. The present analysis suggests traditional breadwinner ideologies continue to influence financial satisfaction assessment in Taiwan.
\end{abstract}

Keywords: Financial satisfaction, gender differences, Taiwan, emotion, trait affect, dispositional affect JEL Codes: I310, D100 


\section{Examining Gender Differences in Predictors of Financial Satisfaction: Evidence from Taiwan}

Financial satisfaction has garnered extensive attention in the past decades, as financial satisfaction is an important predictor of satisfaction with life (Diener \& Oishi 2000). Around the world, financial satisfaction is one of the strongest predictors of subjective well-being ( $\mathrm{Ng} \&$ Diener 2014), predicting as much variance in SWB as occupational, physical health, and relationship satisfaction combined (Netemeyer et al. 2018). This is particularly the case in countries undergoing economic transition, such as Taiwan, where life satisfaction is argued to be more strongly dependent on financial satisfaction (i.e., a "monetarization of happiness;" Brockmann et al. 2009). Although various factors are consistently found to be associated with financial satisfaction, no studies, to our knowledge, have examined how the factors that determine financial satisfaction differ by gender in the Asian context. Furthermore, to our knowledge, no studies have examined how personality traits such as trait affect influence financial satisfaction in an Asian context, although findings from the U.S. have found that trait affect is one of the strongest predictors of financial satisfaction (Tharp 2017; Tharp, Seay, Carswell, et al. 2020).

Much of the research on the determinants of financial satisfaction has been conducted in the United States (see Joo and Grable 2004; Tharp, Seay, Carswell, et al. 2020; Woodyard and Robb 2016; Xiao and O’Neill 2018). However, culture may play an important role in how individuals assess financial satisfaction, and it is therefore important to examine financial satisfaction assessment not only in individualistic cultures such as the U.S., but also more collectivistic cultures like Taiwan (Hofstede 1984; Wu 2006). Furthermore, the traditional gender values in Taiwan make this an ideal population for studying gender differences in financial satisfaction in Asia. As in other Confucian societies, Taiwanese men are expected to be the breadwinner of the family (Chen 2019; Liu 2017) and Taiwanese women continue to prefer husbands with greater economic resources (Cheng 2014). Despite gains in Taiwanese women's workforce participation over recent decades (from 38\% employment in 1978 to $51 \%$ in 2015; Yu 2015), a high proportion of women in Taiwan leave their jobs following marriage or childbirth (Chang 2006). For example, in a nationally representative survey of married women in Taiwan, Yu (2005) found 
$42 \%$ exited the workforce around the time of their marriage. This leaves women disproportionately dependent on their husbands and extended family members for their financial security, and indicates that financial satisfaction in Taiwan may be associated with different factors among women than among men in this cultural context.

Using on an integrative model of top-down and bottom-up influences on financial satisfaction, the present study considers how top-down (trait positive and negative affect) and bottom-up (demographic, financial, and social support) factors may be differently associated with financial satisfaction among men and women in a Taiwanese context. Furthermore, from a social role theory perspective, we examine how gender may moderate financial satisfaction assessment differently within various social contexts (e.g., for those who currently work or for married individuals who work). The present study makes several new contributions to the literature. First, we find evidence supportive of the use of our integrative model of bottom-up and top-down influences on financial satisfaction assessment within a Taiwanese context.

Consistent with research from a U.S. context, we find that trait positive affect and trait negative affect are important predictors of financial satisfaction that have been largely overlooked in the Taiwanese literature. Second, we find that predictors of financial satisfaction, and particularly economic predictors conceptually relevant to breadwinner ideologies (e.g., one's own personal income), do vary between men and women in a Taiwanese context. Third, we find that gender differences vary among predictors within different social contexts. For instance, whereas income is predictive of financial satisfaction for both men and women within a broad sample of Taiwanese respondents, income is only predictive of financial satisfaction among men when analyses are limited to individuals who are working or both married and working in Taiwan.

\section{Background}

\section{Theoretical Basis for Gender Differences in Financial Satisfaction Assessment}

Two dominant theoretical accounts have been put forward to explain life satisfaction in the literature: bottom-up (i.e., situational) and top-down (i.e., dispositional) perspectives (Heller et al. 2004). Both bottom-up perspectives, which posit that an individual's life circumstances influence satisfaction 
assessment (i.e., objective life conditions lead to satisfaction), and top-down perspectives, which posit that personality traits provide enduring affective dispositions toward satisfaction or dissatisfaction, have been supported empirically (Brief et al. 1993). However, integrative models that include both bottom-up and top-down influences have performed best of all (Heller et al. 2004). Furthermore, various bottom-up and top-down influences on satisfaction assessment have been found to be moderated by gender.

Therefore, in this study, we employ an integrative model of bottom-up and top-down influences moderated by gender (see Figure 1).

\section{[Insert Figure 1 about here]}

The differing roles of both top-down and bottom-up influences on satisfaction assessment can also vary within different social contexts. Social role theory posits that the gendered distributions of men and women within various roles in society promotes gender differences in behavior (Eagly 1987; Eagly et al. 2000). As individuals develop within a society and observe men and women disproportionately involved in various roles, expectations and norms regarding how one should behave are developed. These differences are reinforced by societal reward (or punishment) for conformity (or nonconformity) with such norms. One of the most commonly observed gendered roles within societies is the disproportionate division of labor within a household with men as resource providers and women as homemakers (Eagly et al. 2000). These gendered norms may lead to differences between men and women with respect to relationships between financial characteristics (e.g., income, household breadwinner status) and financial satisfaction. For instance, being the breadwinner of one's household may be positively associated with financial satisfaction among men, but not associated (or even negatively associated) with financial satisfaction among women. As such, social context (e.g., marriage status) may moderate the moderating influence of gender on both top-down and bottom-up influences on financial satisfaction. This potential role of social context is conceptualized in Figure 2.

[Insert Figure 2 about here]

Gender differences that are (are not) observed among men and women in the aggregate may not (may) be observed within particular subsamples that reflect this social context. For instance, income may 
predict financial satisfaction among all women differently than it does among married women. Social factors that are relevant within specialized social roles may not be relevant among broader populations. For instance, one's relative contribution toward total household income is a bottom-up factor that is relevant for two person households but not single person households. One's marriage status and employment status are two particularly important social contexts which could lead to varying gender differences in predictors of financial satisfaction. As such, we examine gender differences in predictors of financial satisfaction among three differing social contexts (see Figure 3): (a) all available individuals, (b) only those who are working outside of the household, and (c) only those who are both married and working outside of the household. Moving from (a) to (b) confines the social context to one in which an individual is engaged in market labor. Moving from (b) to (c) confines the social context to one in which two individuals are pooling labor and resources within a household while also both engaged in market labor. Because individuals within each social context can be expected to differ in their constraints and preferences, it is reasonable to anticipate that the factors which predict financial satisfaction may also vary.

Gender differences in bottom-up influences. Bottom-up influences on satisfaction assessment have been found to differ by gender. Previous studies have found that relationships between income and financial satisfaction (Adelmann 1987; Fan and Babiarz 2019) and relative income share and financial satisfaction (Ahn, Ateca-Amestoy, and Ugidos 2014) are moderated by gender. Similarly, demographic characteristics, such as marriage, have been found to be differently associated with financial satisfaction among men and women (Fan and Babiarz 2019). Agrawal et al. (2011) found that whereas men in India with higher incomes reported higher positive emotions than men with lower income, these relationships were not observed among women. Furthermore, although the literature is limited with respect to differing influences on financial satisfaction in particular, it is reasonable to suspect that other bottom-up influences, such as social support, may also be associated with financial satisfaction differently among men and women. 


\section{Gender differences in relationships between demographic characteristics and financial}

satisfaction. In past studies, the relationship between financial satisfaction and bottom-up demographic variables, such as marriage and education, have been inconsistent. Some prior studies have found a positive relationship between marriage and financial satisfaction (Tharp, Seay, Stueve, and Anderson 2020; Woodyard and Robb 2016; Xiao et al. 2014), whereas others have not (Garrett and James 2013; Joo and Grable 2004; Seay et al. 2015). In a sample of U.S. individuals aged 50 and above, Tharp, Seay, Carswell, et al. (2020) found marriage to be positively associated with women's financial satisfaction but not men's, after controlling for personality and a number of other financial characteristics. Compared to married counterparts, Fan and Babiarz (2019) found that single women and divorced individuals regardless of gender exhibited lower levels of financial satisfaction.

In Taiwan, marriage has been found to have a positive relationship with financial satisfaction (Tsou and Liu 2001). Gender differences in this relationship were not explicitly addressed. However, Hori and Kamo (2018) found that marriage was positively associated with men's happiness, but not women's, happiness in Taiwan. As financial satisfaction is a facet of subjective well-being ( $\mathrm{Ng}$ and Diener 2014), these findings may suggest that men would be more likely to show a relationship between marriage and financial satisfaction in Taiwan.

H1: Marriage will be more strongly positively associated with financial satisfaction among men than women.

Education is a second previously-explored bottom-up demographic variable that has had inconsistent relationships with financial satisfaction. Prior studies have found the relationship to be positive (Xiao and Porto 2017), negative (Joo and Grable 2004; Tharp, Seay, Stueve, et al. 2020; Tharp, Seay, Carswell, et al. 2020; Woodyard and Robb 2016; Xiao et al. 2014), and null (DePianto 2011; Garrett and James 2013; Seay et al. 2015). However, education has been found to significantly predict financial satisfaction in Taiwan (Lin et al. 2014; Tsou and Liu 2001). Related findings for life satisfaction suggest that gender may moderate the relationship between education and financial satisfaction. For example, using a nationally representative sample in the U.S., Calasanti (1996) found that whereas 
financial satisfaction and life satisfaction were significantly correlated for both men and women, education significantly predicted men's, but not women's, life satisfaction in retirement. Chen (2012) argues that the association between education and social networks mediates the education-happiness association in Taiwan. Similarly, Lin et al. (2014) highlight the importance of education for political and social capital in Taiwan, and find that it significantly predicts all facets of well-being, including financial well-being. Most importantly for the present study, recent research has demonstrated that in Taiwan education plays an important role in determining women's power to make financial decisions in the family. Specifically, the odds that women participate in family decision making (e.g., career choices, children's education, family expenses, and estate purchases) increase as wives' level of education increases (Xu and Lai 2002). This suggests that education may be especially important for women's financial satisfaction in Taiwan.

H2: Education will be more strongly positively associated with financial satisfaction among women than men.

\section{Gender differences in relationships between financial characteristics and financial}

satisfaction. Income and household income share are both bottom-up contextual factors that may influence men's and women's financial satisfaction. Prior studies have found a positive relationship between income and financial satisfaction (Garrett and James 2013; Seay et al. 2015; Tharp, Seay, Stueve, et al. 2020; Tharp, Seay, Carswell, et al. 2020; Woodyard and Robb 2016; Xiao et al. 2014). In Taiwan, income has been found to significantly predict both overall happiness and financial satisfaction (Chang 2009; Chang 2013; Tsou and Liu 2001). However, demographics like gender have been found to moderate the relationship between income and financial satisfaction (DePianto 2011). In a nationally representative sample of twins in the United States, income was associated with subjective financial wellbeing for men only (Zyphur et al. 2015). The cultural context of Taiwan may also create important gender differences in the relationship between individual income and financial satisfaction. Although women have high participation in the workforce in Taiwan (Wu 2014), there is a strong norm for men to be the breadwinner within marriages in Taiwan and in the similar context of China (Hu and Kamo 2007; Shek 
2006; Zhang 2015). This has implications for subjective well-being. For example, in a sample of Taiwanese adults, working full-time positively predicted men's self-perceived health, whereas women showed positive effects of staying home with their families (Chen et al. 2008). This suggests that personal income may be associated with financial satisfaction for men more than women. In their sample from Taiwan, Lin et al. (2014) pointed out that although women's incomes were significantly less than men's incomes, their financial satisfaction was significantly higher than men's. The authors suggest that this reflects the traditional values of Taiwanese society. Together, this research suggests that in Taiwan, men's financial contributions (i.e., income) and financial circumstances that lead to feelings of fulfilling the breadwinner role (e.g., contributing a larger share of household income) may play a larger role in their financial satisfaction than it does for women.

H3: Income will be more strongly positively associated with financial satisfaction among men than women.

H4: Household income share will be more strongly positively associated with financial satisfaction among married men than women.

Gender differences in relationships between social support and financial satisfaction. Social support is another bottom-up factor considered within the present analysis. Using the Gallop World Poll, $\mathrm{Ng}$ and Diener (2014) found social support positively predicted financial satisfaction at the individual level. In Taiwan, social support has been found to predict women's (but not men's) happiness (Hori and Kamo 2018). However, in their analysis of subjective well-being in Taiwan, Lin et al. (2014) found that financial well-being and social-related factors (e.g., community, family, friendship, as well as mental and physical health) loaded on different underlying factors of subjective well-being, and therefore may not show a relationship.

H5: Social support will be more strongly associated with financial satisfaction among women than men.

Gender differences in top-down influences. Top-down influences on satisfaction assessment, such as one's personality, tend to be stable over time (Cobb-Clark and Shurer 2012) and provide an 
enduring disposition towards satisfaction or dissatisfaction (Heller et al. 2004). Unlike most bottom-up influences, there may be some degree of biological influence on top-down influences, as characteristics such as Big Five personality traits (openness to experience, conscientiousness, agreeableness, extraversion, and neuroticism) have been found to be heritable (Loehlin et al. 1998). However, consistent with social role theory (Eagly 1987; Eagly et al. 2000), it is also possible that much of the gender differences observed in personality stem from conditioning to comply with social norms. Regardless of whether gender differences in top-down influences stem from social or biological sources (most likely a complicated combination of both), gender differences in characteristics such as personality traits have been observed consistently across cultures (Costa, Terracciano, and McCrae 2001; McCrae and Terracciano 2005), and top-down influences have generally been found to play a larger role in predicting financial satisfaction in comparison to bottom-up influences (Tharp, Seay, Carswell, et al. 2020).

Gender differences in relationships between trait affect and financial satisfaction. Trait (or dispositional) affect is of particular importance to financial satisfaction assessment. Unlike momentary affect, which is more volatile and subject to fluctuation based on present conditions, trait affect is an enduring disposition towards positive or negative emotionality akin to a personality trait that is stable over time and across situations (Watson and Walker 1996). General dispositions towards positive and negative emotions are likely to influence how one responds to questions such as, "How satisfied are you with your present financial situation?" Emotions associated with positive affect (e.g., feeling happy, confident, alert) tend to co-occur both within and between individuals, as do responses on negative affect items (e.g., anger, sadness; Watson and Clark 1992). Findings from the U.S. have found that trait affect is one of the strongest predictors of financial satisfaction (Tharp 2017; Tharp, Seay, Carswell, et al. 2020). Thus, trait positive and negative affect are included as predictors in the present model to examine whether these predictors vary by gender in the Taiwanese context.

Past studies have indicated that trait positive and negative affect are positively and negatively associated with financial satisfaction, respectively (Ng and Diener 2014; Tharp, Seay, Carswell, et al. 2020). Using the Gallop World Poll, Ng and Diener (2014) found financial satisfaction at the individual 
level was positively correlated with positive affect (.25) and negatively correlated with negative affect (.21). Gender differences have been observed in negative affect across cultures (Fujita et al. 1991; Lucas and Gohm 2000; Zuckerman et al. 2017), with women generally reporting higher levels of negative affect. However, there has been conflicting findings on gender differences in the relationship between negative affect and financial well-being, with some predicting a stronger relationship between negative affect and financial strain for women (Krause 1986), for men (Mendes de Leon et al. 1994), or no differences (Chi and Chou 2000). The current analysis therefore examines relationships between positive and negative affect and financial satisfaction for both men and women.

H6: Trait positive affect will be positively associated with financial satisfaction among both men and women.

H7: Trait negative affect will be negatively associated with financial satisfaction among both men and women.

In summary, existing research demonstrates the importance of considering both bottom-up and top-down influences on satisfaction assessment. In this study, we employ an integrative model of bottomup and top-down factors to examine gender differences in predictors of financial satisfaction between men and women in Taiwan. Furthermore, we examine how gender differences may vary within different social contexts, consistent with a social role theory perspective.

\section{Data and Methods}

The data used in this analysis is the 2016 wave of the Panel Study of Family Dynamics (PSFD). The PSFD, developed by Academic Sinica, is conducted on a biennial basis and includes respondents from both the southeast coastal region of China and Taiwan. A total of 4,774 individuals were included in the 2016 dataset. Because only 40 individuals within the PSFD reside in China and because the social 
context between China and Taiwan may vary, we limit our analysis to solely individuals from Taiwan. ${ }^{1}$

Descriptive statistics for each analytic sample are provided in Table 1.

[Insert Table 1 about here]

\section{Dependent Variable}

The dependent variable used in this study is financial satisfaction. Respondents in the PSFD were asked "Are you satisfied with your current financial situation?" Potential responses included very dissatisfied, somewhat dissatisfied, somewhat satisfied, and very satisfied. Financial satisfaction is treated as an ordinal variable within all subsequent analyses given the ordinal nature of this measure.

\section{Predictor Variables}

The following bottom-up and top-down variables are included within this analysis as predictor variables.

Bottom-Up Predictors: Demographic Characteristics. Marital status (single, married, divorced, separated, and widowed) and education (no education, less than high school education, high school, vocational or similar, college, and graduate degree or higher) are entered as categorical variables.

Bottom-Up Predictors: Financial Characteristics. Financial characteristics vary in each analysis by model, but include: natural log transformed respondent income, natural log transformed spouse's income, household income share (percent of total household income earned by a respondent), household income adequacy (natural log of total household income divided by natural log of total household expenses), average hours worked per week, and job satisfaction. Income has been used in almost all prior analyses of financial satisfaction (e.g., see Tharp 2017 for a summary of predictors included in prior analyses). Ahn et al. (2014) utilized a similar measure of household income share ${ }^{2}$. Our

\footnotetext{
${ }^{1}$ The analytic sample for our first regression analysis is 3,593 due to missing data. After excluding individuals living outside of Taiwan, data were missing at the highest rates for responses related to household expenses $(\mathrm{n}=$ $1,015)$ and income $(\mathrm{n}=184)$.

${ }^{2}$ Ahn et al. (2014) refer to their measure as "share of own labour income" which does differ in that we do not distinguish between labor and non-labor income. However, our measure is largely intended to capture the same dynamic of relative contributions to household income.
} 
measure of household income adequacy is, to our knowledge, unique to the financial satisfaction literature. However, our income adequacy measure is based on the common notion of assessing whether a household's income is sufficient to cover expenses. Conceptually similar measures, such as a household's difficulty paying bills, have been used extensively in the financial satisfaction literature (Seay et al. 2015; Tharp, Seay, Carswell et al. 2020; Tharp, Seay, Stueve et al. 2020; Woodyard and Robb 2016). Hours worked has previously been noted to be of theoretical importance to financial satisfaction (Choi 2001) and used as a predictor of financial satisfaction (Marley et al. 2011). Additionally, job satisfaction (measured on a four-point Likert-type scale from very dissatisfied to very satisfied, treated as a continuous variable) is included as a bottom-up predictor within samples of individuals who are working.

Bottom-Up Predictor: Social Support. Exploratory factor analysis (EFA) was conducted to reduce the dimensionality of the 14 psychosocial variables included in the 2016 wave of the PSFD to distinguish between the bottom-up factors of social support and the top-down factors of trait positive and negative affect. Questions within the PSFD were drawn from the MOS 36-Item Short Form Health Survey (SF-36; Ware Jr. and Sherbourne 1992), the State-Trait Anxiety Inventory Form Y-2 (STAI; Spielberger et al. 1983), and the Center for Epidemiologic Studies Depression Scale (CES-D; Radloff 1977). However, none of the scales were included in full. Three factors were extracted and retained as continuous measures in this analysis. As explained further in the results, we interpret these factors as social support (a bottom-up factor) and trait positive and negative affect (top-down factors), as the question stems for the underlying questions were consistent with measure of trait rather than state affect (see Watson and Clark 1999).

Top-Down Predictors: Positive and Negative Affect. Trait positive affect was comprised of Likert-type scale questions related to feelings of happiness, safety, calmness, and being at ease, whereas trait negative affect consisted of questions related to feeling nervous, worried, depressed, unable to feel happy, and an inability to overcome obstacles.

\section{Analyses}


A series of generalized ordered logistic regression analyses were then conducted to explore gender differences in the relationships between financial satisfaction and top-down (trait positive and negative affect) and bottom-up (demographic, financial, and social support) factors within three subsamples of the 2016 wave of the PSFD: all individuals, working individuals, and both married and working. The generalized ordered logistic model is used given that this model is less restrictive than proportional odds models yet more parsimonious than alternative models, such as multinomial logistic regression, that disregard the ordinal nature of a dependent variable (Williams, 2016). The first sample included all respondents without missing data $(\mathrm{n}=3,593)$. To examine work-related factors (e.g., job satisfaction, hours worked), we then restricted the second analysis to only those who were currently working $(n=2,713)$. Within the PSFD, working status is defined as those who are employed outside of the home or conduct at least 15 hours per week of unpaid labor for family members. To examine relationship-related factors (e.g., spousal income, share of household income), we restricted the third analysis to individuals who were both married and working $(\mathrm{n}=1,306)$. Per Williams $(2006)$, an example of the generalized ordered logistic model with $\mathrm{M}$ categories and $\mathrm{N}$ predictor variables can be expressed as:

$$
P\left(Y_{i}>j\right)=\frac{\exp \left(\alpha_{j}+X 1_{i} \beta 1+X 2_{i} \beta 2_{j}+\ldots X N_{i} \beta N_{j}\right)}{1+\left[\exp \left(\alpha_{j}+X 1_{i} \beta 1+X 2_{i} \beta 2_{j}+\ldots X N_{i} \beta N_{j}\right)\right]}, j=1,2, \ldots, M-1
$$

The example above illustrates a case in which $\beta$ 's for $X 1$ are the same but vary among $X 2$ for all values of $j$. This example is simply intended to illustrate how the generalized ordered logistic regression can differ from a standard ordered logistic regression via relaxation of the proportional odds assumption when needed, while still potentially estimating fewer parameters if assumptions are met.

To examine gender differences in predictors of financial satisfaction, we first include each variable within our model interacted with gender. We do not include main effects along with the interactions specified, which yields simple effects which are varied by gender (UCLA: Statistical Consulting Group n.d.). Furthermore, the exclusion of main effects does not influence the overall fit of 
our model. Rather, this exclusion is simply a reparameterization of a model inclusive of main effects (UCLA: Statistical Consulting Group n.d.).

Additionally, consistent with Ahn et al. (2014), separate generalized ordered logistic regression analyses were conducted for males and females within each sample individually. These parameters estimated in these analyses are not materially different than the estimates provided in our models with interaction terms ${ }^{3}$. We run these analyses separately for the purposes of being able to compute marginal effects that ease the interpretation of our results. Because marginal effects are easier to interpret and these regression results are not materially different from the results when modeled with an interaction term, our presentation of results and discussion focus on the marginal effect results. For categorical variables, average marginal effects are reported for between-group comparisons; for continuous variables, average marginal effects are based on a one standard deviation increase in the continuous variable. Standard deviations were calculated for the full analytic sample among each subsample (i.e., including both males and females) in order to standardize the marginal effect comparisons between genders.

\section{Results}

\section{Exploratory Factor Analysis}

In preparation for the regression analyses, exploratory factor analysis (EFA) using maximum likelihood was conducted on all available respondents $(n=4,774)$ to reduce the dimensionality of the psychosocial variables included within the PSFD, ultimately distinguishing between the top-down factors of trait positive and negative affect and the bottom-up factor of social support. Thirty respondents were excluded due to missing data. Preliminary checks of the data confirmed the assumptions outlined in Laerd Statistics (2015): all variables were correlated with at least one other variable at a level of 0.3 or higher, Bartlett's Test of Sphericity was statistically significant $(p<0.001)$, the Kaiser-Meyer-Olkin (KMO) measure of sampling adequacy was 0.895 , and all individual KMO measures were greater than 0.8 -

\footnotetext{
${ }^{3}$ Results are available from the authors upon request.
} 
indicating a level of factorial simplicity of "meritorious" according to guidelines established by Kaiser (1974).

Three components had eigenvalues greater than one. During an initial analysis, "no appetite" and "difficulty sleeping" loaded at levels of less than 0.4 , so they were removed from the analysis and the EFA was re-run. Each item loaded substantially (component loading greater than 0.4 ) on only one component after Promax rotation using a Kappa value of 4 (Hendrickson and White 1964). The Promax rotation was chosen because the rotated solution using this method exhibited a simple structure (Thurstone 1947) and was interpretable. We interpret the components as (a) trait positive affect (comprised of questions related to feelings of happiness, safety, calmness, and being at ease), (b) negative trait affect (comprised of questions related to feeling nervous, worried, depressed, unable to feel happy, and an inability to overcome obstacles), and (c) social support (comprised of questions related to feelings of not being liked by others, others not being friendly towards me, and loneliness). We interpret these factors as trait (i.e., enduring) rather than state (i.e., momentary) affect because the question stem from the PSFD asked respondents to think back over the past month, which is a time horizon consistent with the measurement of trait affect (Watson and Clark 1999). ${ }^{4}$ Rotated factor loadings from the PCA are reported in Table 2. Rotated component scores were retained for each respondent for use within regression analyses.

\section{[Insert Table 2 about here]}

\section{Regression Analyses}

A series of six generalized ordered logistic regressions analyses (three per gender) were then conducted to explore how associations between bottom-up (demographic, financial, and social support) and top-down (trait positive and negative affect) factors were associated with financial satisfaction by gender.

\footnotetext{
${ }^{4}$ We also note that, although the authors of the PSFD did not use any scales in full, the items selected had reasonable conceptual overlap with items from the PANAS-X (Watson and Clark 1999). Additionally, of the items selected from the STAI (Spielberger et al. 1983), both were trait rather than state measures of anxiety.
} 
Full sample results. The regression results for the analysis among the full sample are reported in Table 3.

Bottom-up: Demographic characteristics. Demographic factors were associated with males' and females' financial satisfaction. Marital status was associated with financial satisfaction among both males and females, but this relationship was generally stronger among men. For both genders, only divorced respondents differed from the other marital categories, and divorce was strongly negatively associated with financial satisfaction, particularly among males. For example, among males, being married compared to being divorced was associated with an 10.9 percentage point increase in the probability of reporting being somewhat satisfied with one's financial situation $(p<.01)$ and a 9.0 percentage point decrease in the probability of reporting being somewhat dissatisfied $(p<.01)$. By contrast, among females, being married compared to being divorced was not associated with the probability of reporting being somewhat satisfied with one's financial situation but was associated with a 5.2 percentage point decrease in the probability of reporting being somewhat dissatisfied $(p<.1)$. Education was generally more strongly associated with financial satisfaction among women than men, although significant effects were not found for every comparison group. Where significant associations were observed, education was generally positively associated with financial satisfaction. Social support was not associated with financial satisfaction among either gender.

Bottom-up: Financial characteristics and social support. Economic factors were generally more strongly associated with financial satisfaction among men compared to women. While respondent income was positively associated with financial satisfaction among both men and women, stronger relationships with larger effect sizes were generally observed among men. For instance, a one standard deviation increase in $\log$ respondent income was associated with a 41.2 percentage point increase in the probability of reporting feeling very satisfied with one's financial situation $(p<.001)$ among men but was not associated with financial satisfaction among women. Similarly, a one standard deviation increase in log respondent income was associated with a 15.1 percentage point reduction in the probability of reporting feeling somewhat dissatisfied with one's financial situation among men $(p<.001)$ but was only 
associated with a 5.7 percentage point reduction in the probability of reporting feeling somewhat dissatisfied among women $(p<.05)$. Household income adequacy was not associated with financial satisfaction among either gender at a level of $p<.1$. Large gender differences in work status as a predictor of financial satisfaction were observed. For instance, among men, currently working was associated with a 76.4 percentage point decrease in the probability of reporting being very satisfied with one's financial situation $(p<.001)$, while not working was not associated with the probability of reporting being very satisfied with one's financial situation among women. Among men, currently working was also associated with a 53.9 percentage point increase in the likelihood of reporting being somewhat satisfied ( $p$ $<.001)$ and a 24.4 percentage point increase in the likelihood of reporting being somewhat dissatisfied $(p$ $<.05)$. Among women, currently working was associated with a 9.5 percentage point decrease in the likelihood of reporting being somewhat satisfied $(p<.05)$, a 9.7 percentage point increase in the likelihood of reporting being somewhat dissatisfied $(p<.05)$, and a 4.1 percentage point increase in the likelihood of reporting being extremely dissatisfied $(p<.1)$.

Top-down: Positive and negative affect. Trait positive affect was strongly positively associated with financial satisfaction for both males and females. A one standard deviation increase in trait positive affect was associated with a 2.9 percentage point (males) and 2.7 percentage point (females) reduction in the probability of reporting being very dissatisfied with one's financial situation, a 9.4 percentage point (males) and 7.8 percentage point (females) reduction in the probability of reporting feeling somewhat dissatisfied, a 6.6 percentage point (males) and 3.0 percentage point (females) increase in the probability of reporting feeling somewhat satisfied, and a 9.2 percentage point (males) and 3.9 percentage point (females) increase in the probability of reporting feeling very satisfied. Trait negative affect was more strongly negatively associated with financial satisfaction among females than males. Among females, a one standard deviation increase in negative emotion was associated with a 2.0 percentage point increase in the probability of reporting feeling very dissatisfied $(p<.001)$, a 4.4 percentage point increase in the probability of reporting feeling somewhat dissatisfied $(p<.001)$, a 5.0 percentage point decrease in the probability of reporting feeling somewhat satisfied $(p<.001)$, and a 1.4 percentage point decrease in the 
probability of reporting feeling very satisfied $(p<.001)$. Among men, a one standard deviation increase in trait negative affect was associated with a 2.3 percentage point increase in the probability of reporting feeling extremely dissatisfied $(p<.05)$ and a 4.7 percentage point decrease in the probability of reporting feeling somewhat satisfied $(p<.05)$.

[Insert Table 3 about here]

Working sample results. The regression results for the analysis of working individuals are reported in Table 4.

Bottom-up: Demographic characteristics. Marital status was again the demographic variable most commonly associated with financial satisfaction among both males and females. Generally speaking, divorce was negatively associated with financial satisfaction among both males and females, while being widowed (versus divorced) was positively associated with financial satisfaction among only females. Education was more commonly associated with financial satisfaction among females than males.

Bottom-up: Financial characteristics and social support. Economic factors considered were associated with financial satisfaction among both males and females. Log respondent income was positively associated with financial satisfaction among males but not females. A one standard deviation increase in log respondent income was associated with 0.9 percentage point reduction in the probability of reporting feeling very dissatisfied with one's financial situation $(p<.01)$, a 3.1 percentage point reduction in the probability of reporting feeling somewhat dissatisfied $(p<.01)$, a 2.9 percentage point increase in the probability of reporting feeling somewhat satisfied $(p<.01)$, and 1.1 percentage point increase in the probability of reporting feeling very satisfied $(p<.05)$. Household income adequacy was positively associated with financial satisfaction among females but not males. A one standard deviation increase in household income adequacy was associated with 0.9 percentage point reduction in the probability of reporting feeling very dissatisfied with one's financial satisfaction $(p<.01)$, a 2.7 percentage point reduction in the probability of reporting feeling somewhat dissatisfied $(p<.01)$, a 2.7 percentage point increase in the probability of reporting feeling somewhat satisfied $(p<.01)$, and 0.8 percentage point increase in the probability of reporting feeling very satisfied $(p<.05)$. Hours worked was a significant 
predictor of financial satisfaction among both men and women. Among men, a one standard deviation increase in hours worked was associated with a 1.2 percentage point decrease in the probability of reporting feeling very dissatisfied with one's financial situation $(p<.05)$, a 2.0 percentage point decrease in the likelihood of reporting feeling somewhat dissatisfied $(p<.05)$, and a 1.4 percentage point increase in the likelihood of reporting feeling extremely satisfied. Among women, a one standard deviation increase in hours worked was associated with a 2.5 percentage point reduction in the probability of reporting feeling somewhat dissatisfied with one's financial situation $(p<.05)$ and a 2.8 percentage point increase in the probability of reporting feeling somewhat satisfied $(p<.1)$. A one standard deviation increase in job satisfaction was associated with a 2.0 percentage point (males; $p<.001$ ) and 2.1 percentage point (females; $p<.001$ ) reduction in the probability of reporting being very dissatisfied with one's financial situation, an 7.7 percentage point (males; $p<.001$ ) and 6.6 percentage point (females; $p<$ .001) reduction in the probability of reporting feeling somewhat dissatisfied, a 3.4 percentage point (males; $p<.01$ ) and 3.6 percentage point (females; $p<.05$ ) increase in the probability of reporting feeling somewhat satisfied, and a 6.4 percentage point (males; $p<.001$ ) and 4.9 percentage point (females; $p<$ .001) increase in the probability of reporting feeling very satisfied. Social support was not associated with financial satisfaction among either gender within the working sample.

Top-down: Positive and negative affect. Trait positive and negative affect were associated with financial satisfaction among both males and females within the sample of working individuals. Trait positive affect was strongly positively associated with financial satisfaction among both men and women, whereas trait negative affect was only negatively associated with financial satisfaction among females. All associations between trait positive affect and financial satisfaction were significant at a level of $p<$ .001. A one standard deviation increase in positive emotion was associated with a 2.1 percentage point (males) and 1.7 percentage point (females) reduction in the probability of reporting being very dissatisfied with one's financial situation, a 7.8 percentage point (males) and 5.5 percentage point (females) reduction in the probability of reporting feeling somewhat dissatisfied, a 6.5 percentage point (males) and 5.3 percentage point (females) increase in the probability of reporting feeling somewhat satisfied, and a 3.3 
percentage point (males) and 1.8 percentage point (females) increase in the probability of reporting feeling very satisfied.

[Insert Table 4 about here]

Married and working sample results. The regression results for the analysis among only individuals who were both married and working individuals are reported in Table 5.

Bottom-up: Demographic characteristics. Age and age squared were significant predictors of financial satisfaction among women but not men. Specifically, a one standard deviation increase in age was associated with a 22.6 percentage point increase in the likelihood of reporting feeling somewhat dissatisfied with one's financial situation among women $(p<.001)$ and a 4.0 percentage point decrease in the likelihood of reporting feeling very satisfied $(p<.01)$. Additionally, one standard deviation increase in age squared was associated with a 3.2 percentage point decrease in the probability of reporting feeling very dissatisfied $(p<.05)$, a 17.4 percentage point decrease in the probability of reporting feeling somewhat dissatisfied $(p<.1)$, and a 10.6 percentage point increase in the probability of reporting feeling somewhat satisfied $(p<.001)$. Education was not associated with financial satisfaction among married and working men or women.

Bottom-up: Financial characteristics and social support. Gender differences in economic factors as predictors of financial satisfaction were observed within this sample. Log respondent income was positively associated with financial satisfaction only among males. Among males, a one standard deviation increase in log respondent income was associated with 1.6 percentage point reduction in the probability of reporting feeling very dissatisfied with one's financial satisfaction $(p<.01)$, a 7.3 percentage point reduction in the probability of reporting feeling somewhat dissatisfied $(p<.01)$, a 4.7 percentage point increase in the probability of reporting feeling somewhat satisfied $(p<.001)$, and 4.1 percentage point increase in the probability of reporting feeling very satisfied $(p<.05)$. Household income adequacy was more strongly associated with financial satisfaction among females than males. Among men, a one standard deviation increase in household income adequacy was associated with 0.7 percentage point reduction in the probability of reporting feeling very dissatisfied with one's financial 
satisfaction $(p<.05)$, a 2.9 percentage point reduction in the probability of reporting feeling somewhat dissatisfied $(p<.05)$, a 2.2 percentage point increase in the probability of reporting feeling somewhat satisfied $(p<.01)$, and 1.4 percentage point increase in the probability of reporting feeling very satisfied $(p<.05)$. Among women, a one standard deviation increase in household income adequacy was associated with an 8.1 percentage point decrease in the likelihood of reporting feeling somewhat dissatisfied with one's financial situation $(p<.001)$ and a 7.5 percentage point increase in the likelihood of reporting feeling somewhat satisfied $(p<.01)$. Hours worked was only a significant predictor of financial satisfaction among women at a level of $p<.05$. Among women, a one standard deviation increase in hours worked was associated with a 3.9 percentage point decrease in the likelihood of reporting feeling somewhat dissatisfied with one's financial situation $(p<.05)$ and a 4.5 percentage point increase in the likelihood of reporting feeling somewhat satisfied $(p<.05)$. Log spouse income and household income share were generally not significant predictors of financial satisfaction among either gender within the married and working sample. A one standard deviation increase in job satisfaction was associated with a 1.6 percentage point (males; $p<.001)$ and 1.6 percentage point (females; $p<.01)$ reduction in the probability of reporting being very dissatisfied with one's financial situation, an 7.8 percentage point (males; $p<.001$ ) and 7.7 percentage point (females; $p<.001$ ) reduction in the probability of reporting feeling somewhat dissatisfied, a 4.8 percentage point (males; $p<.001$ ) increase among males but not females in the probability of reporting feeling somewhat satisfied, and a 4.5 percentage point (males; $p<.001$ ) and 7.7 percentage point (females; $p<.001$ ) increase in the probability of reporting feeling very satisfied. Social support was associated with financial satisfaction among females but not males. Specifically, among women, a one standard deviation in social support was associated with a 0.9 percentage point decrease in the probability of reporting being very dissatisfied with one's financial situation $(p<.05)$, a 3.9 percentage point decrease in the probability of reporting being somewhat dissatisfied $(p<.05)$, a 3.6 percentage point increase in the probability of reporting being somewhat satisfied $(p<.01)$, and a 1.2 percentage point increase in the probability of reporting being very satisfied $(p<.05)$. 
Top-down: Positive and negative affect. Trait positive and negative affect were associated with financial satisfaction among both males and females within the married and working sample. Job satisfaction and trait positive affect were both strongly positively associated with financial satisfaction. A one standard deviation increase in trait positive affect was associated with a 1.6 percentage point (males; $p<.001$ ) and 1.3 percentage point (females; $p<.01$ ) reduction in the probability of reporting being very dissatisfied with one's financial situation, a 7.4 percentage point (males; $p<.001$ ) and 5.8 percentage point (females; $p<.001$ ) reduction in the probability of reporting feeling somewhat dissatisfied, a 4.7 percentage point (males; $p<.001$ ) and 5.2 percentage point (females; $p<.001$ ) increase in the probability of reporting feeling somewhat satisfied, and a 4.2 percentage point (males; $p<.001$ ) and 1.9 percentage point (females; $p<.05$ ) increase in the probability of reporting feeling very satisfied. Trait negative affect was not associated with financial satisfaction among either males or females.

[Insert Table 5 about here]

\section{Discussion}

Few prior studies had examined financial satisfaction among individuals in Taiwan, and no studies, to our knowledge, had examined gender differences in this population. Furthermore, no prior studies had used an integrative model of both top-down and bottom-up influences of financial satisfaction in a Taiwanese context. The present study identified several relationships between financial satisfaction and top-down and bottom up factors that either confirmed past findings in other contexts or provided new directions for future research.

First, this study provides support for an integrative model of both bottom-up and top-down influences on financial satisfaction assessment within a Taiwanese context. In addition to the bottom-up factors that were observed to be associated with financial satisfaction (e.g., income and work status), we also observed that top-down factors (e.g., trait positive affect and trait negative affect) were associated with financial satisfaction assessment. Consistent with findings regarding trait affect in an American context (Tharp et al. 2020), we find evidence that personality traits may provide enduring affective dispositions towards satisfaction or dissatisfaction in a Taiwanese context. Future consumer wellbeing 
research in a Taiwanese context should consider incorporating integrative models of both top-down and bottom-up influences, since the omission of either could bias results.

Second, this study found that gender can play a moderating role in financial satisfaction assessment within a Taiwanese context. A high-level summary of findings across each social context is provided in Figure 4. While we are exercising some subjectivity in concluding whether a gender difference was observed among predictors within a broad category, generally speaking, gender differences in predictors were seen across a number of variables and social contexts. For instance, among the full sample, gender differences in either significance or effect size of predictors were observed among demographic characteristics (bottom-up; Hypotheses $1 \&$ 2), financial characteristics (bottom-up; Hypotheses $3 \& 4$ ), trait positive and negative affect (top-down; Hypotheses $6 \& 7$ ). Among the full sample, the only key variable in which gender differences was not observed was social support (Hypothesis 5), which itself was not a significant predictor of financial satisfaction among men or women within this analysis. At a high level, results were similar among working individuals in the second sample, with the exception that gender differences in the influence of trait positive affect were less apparent. Among those who were married and working, high-level results were similar to working individuals, with the exception that social support was a significant predictor of financial satisfaction that did vary by gender (Hypothesis 5).

\section{[Insert Figure 4 about here]}

As is also illustrated in Figure 4, differences in predictors and the role of gender in moderating relationships also varied by social context. This was particularly true among financial variables, which are likely some of the factors most heavily influenced by social roles. For instance, while income was a predictor of financial satisfaction among both men and women in the full sample (albeit a predictor with substantial variation in effect sizes by gender), income was only a significant predictor of financial satisfaction among men within the working and married working subsamples. Because social roles can be different for men and women within the contexts of both work and marriage, it is not surprising that one's income could be differently related to financial satisfaction within different social contexts. 
While beyond the scope of this study, it may be the case, for instance, that one's personal income plays a different role in financial satisfaction for single women compared to married women in a Taiwanese context. When one's own sustenance depends solely on personal income, personal income may play a larger role in financial satisfaction assessment, but once individuals pool resources as part of a household, then social gender roles may have a greater influence on factors which predict financial satisfaction. Past research with twins examining gender differences in income and financial well-being suggests that environmental influences, not genes, are responsible for gender differences in the relationship between income and subjective financial well-being (Zyphur et al. 2015). This further speaks to the importance of culture in driving men's focus on their own income in determining their financial satisfaction, which aligns with past research on the importance of paid work for men in China (Zuo 2003). In line with work showing the importance of the breadwinner role for men in modern Chinese marriages (Long et al. 2015; Shek 2006; Zhang 2015; Zuo 2003), these findings suggest that income may be more important to men in Taiwan than women.

Our findings with respect to the varying predictors of financial satisfaction within different social contexts may be informative to other studies of financial satisfaction internationally. Studies to date have largely overlooked social context and the ways in which being situated within a particular social or cultural context may influence financial satisfaction assessment. This is worthy of consideration not only from the perspective of employment and family-related social contexts, but also the ways in which peer groups, community norms, and life cycle stages may also influence financial satisfaction assessment.

Our analyses uncovered other gender differences that warrant further investigation. In contrast to a negative association between education and financial satisfaction in some studies using samples drawn from the United States (e.g., Joo and Grable 2004; Tharp, Seay, Carswell, et al. 2020; Tharp, Seay, Stueve, et al. 2020; Woodyard and Robb 2016; Xiao et al. 2014), this study more commonly found positive associations between education and financial satisfaction among women than among men. The increasingly large disparities in life and financial satisfaction in China between those who are less- and better-educated (Easterlin et al. 2012) may help to explain these findings. Furthermore, whereas financial 
education has been found to impact financial satisfaction through financial literacy, behavior, and capability (Xiao and Porto 2017), the mechanisms by which general educational attainment level affects financial satisfaction are less clear. Future research should examine this relationship.

Including top-down variables like trait positive affect and trait negative affect also allowed a more nuanced view of the predictors of financial satisfaction. Whereas financial satisfaction was associated with higher positive affect in both men and women, associations between negative affect and financial satisfaction were only found for female respondents. The observed gender differences highlight the importance of separately analyzing men and women in future studies of the correlates of financial satisfaction. Furthermore, this top-down relationship between personality and financial satisfaction assessment — and potential moderating role of gender on this top-down influence-warrants future research within a Taiwanese context.

There are some limitations with the present analysis. First, this analysis uses cross-sectional data from a single wave of the PSFD and, therefore, we are limited in our ability to identify causal relationships. For instance, while trait positive affect has generally been found to be stable and enduring trait (e.g., see Watson and Clark 1999), it is possible that financial satisfaction is itself a cause of positive or negative affect. Future studies can expand on the present analysis by exploring how various factors are associated with financial satisfaction on a longitudinal basis. Additionally, the PSFD is not a nationallyrepresentative survey of Taiwan, and therefore there are concerns about how generalizable these findings may be. Furthermore, there were a number of individuals dropped from the PSFD for this analysis due to missing data. While descriptive statistics did not reveal any major differences after dropping respondents with missing data ${ }^{5}$, it is possible these missing data were not missing at random. Nonetheless, due to the

\footnotetext{
${ }^{5}$ After dropping missing respondents from our first model (all adults), log income (7.96 versus 7.57 among the full sample without dropping missing respondents) and college graduate classification (31.8\% versus $29.4 \%$ ) were slightly higher among those remaining, but average financial satisfaction did not differ between groups (2.66 versus 2.66).
} 
limited number of studies which have examined financial satisfaction in Taiwan, we believe the present study provides important initial findings that warrant further investigation.

\section{Conclusion}

The present study represents a first step in understanding gender differences in the relationships between financial satisfaction and a number of top-down (trait positive and negative affect) and bottomup (demographic, financial, and social support) factors in a Taiwanese context. Our findings highlight the importance of gender and social context when determining predictors of financial satisfaction, especially when considering the impact of personal income. In line with past research pinpointing environmental and cultural factors in gender differences in the impact of income on subjective financial well-being (Zyphur et al. 2015), the present analysis suggests traditional breadwinner ideologies may continue to impact financial satisfaction assessment for men and women in a Taiwanese context. 


\section{References}

Adelmann, P. K. (1987). Occupational complexity, control, and personal income: Their relation to psychological well-being in men and women. Journal of Applied Psychology, 72(4), 529-537.

Agrawal, J., Murthy, P., Philip, M., Mehrotra, S., Thennarasu, K., John, J. P., ... \& Isaac, M. (2011). Socio-demographic correlates of subjective well-being in urban India. Social Indicators Research, 101(3), 419-434.

Ahn, N., Ateca-Amestoy, V., \& Ugidos, A. (2014). Financial satisfaction from an intra-household perspective. Journal of Happiness Studies, 15(5), 1109-1123.

Brief, A. P., Butcher, A. H., George, J. M., \& Link, K. E. (1993). Integrating bottom-up and top-down theories of subjective well-being: The case of health. Journal of Personality and Social Psychology, 64(4), 646-653.

Brockmann, H., Delhey, J., Welzel, C., \& Yuan, H. (2009). The China puzzle: Falling happiness in a rising economy. Journal of Happiness Studies, 10(4), 387-405.

Calasanti, T. M. (1996). Gender and life satisfaction in retirement: An assessment of the male model. The Journals of Gerontology Series B: Psychological Sciences and Social Sciences, 51(1), S18-S29.

Chang, C. F. (2006). The employment discontinuity of married women in Taiwan: Job status, ethnic background and motherhood. Current Sociology, 54(2), 209-228.

Chang, W. C. (2009). Religious attendance and subjective well-being in an Eastern-culture country: Empirical evidence from Taiwan. Marburg Journal of Religion, 14(1),

Chang, W. C. (2013). Climbing up the social ladders: Identity, relative income, and subjective well-being. Social Indicators Research, 113(1), 513-535.

Chen, D. R., Chang, L. Y., \& Yang, M. L. (2008). Gender-specific responses to social determinants associated with self-perceived health in Taiwan: A multilevel approach. Social Science \& Medicine, 67(10), 1630-1640.

Chen, W. C. (2012). How education enhances happiness: Comparison of mediating factors in four East Asian countries. Social Indicators Research, 106(1), 117-131. 
Chen, Y. Z. (2019). Exploring identities and practices of Taiwanese men working in family day care: A tentative typology. Journal of Gender Studies, 28(8), 883-894.

Cheng, YA. (2014). Changing partner choice and marriage propensities by education in post-industrial Taiwan, 2000- 2010. Demographic Research, 31(33), 1007-1042.

Chi, I., \& Chou, K. L. (2000). Financial strain and depressive symptoms among Hong Kong Chinese elderly: A longitudinal study. Journal of Gerontological Social Work, 32(4), 41-60.

Choi, N. G. (2001). Relationship between life satisfaction and postretirement employment among older women. The International Journal of Aging and Human Development, 52(1), 45-70.

Cobb-Clark, D. A., \& Schurer, S. (2012). The stability of big-five personality traits. Economics Letters, $115(1), 11-15$.

Costa Jr, P. T., Terracciano, A., \& McCrae, R. R. (2001). Gender differences in personality traits across cultures: robust and surprising findings. Journal of Personality and Social Psychology, 81(2), 322331.

DePianto, D. E. (2011). Financial satisfaction and perceived income through a demographic lens: Do different race/gender pairs reap different returns to income? Social Science Research, 40(3), 773783.

Diener, E., \& Oishi, S. (2000). Money and happiness: Income and subjective well-being across nations. In E. Diener \& E. M. Suh (Eds.), Culture and subjective well-being (pp. 185-218). Cambridge, MA, US: The MIT Press.

Eagly, A. H. (1987). Sex differences in social behavior: A social-role interpretation. Hillsdale, NJ: Lawrence Erlbaum Associates.

Eagly, A. H., Wood, W., \& Diekman, A. B. (2000). Social role theory of sex differences and similarities: A current appraisal. In T. Eckes \& H. M. Trautner (Eds.), The developmental social psychology of gender (pp. 123-174). Mahwah, NJ: Erlbaum.

Easterlin, R. A., Morgan, R., Switek, M., \& Wang, F. (2012). China's life satisfaction, 19902010. Proceedings of the National Academy of Sciences, 109(25), 9775-9780. 
Fan, L., \& Babiarz, P. (2019). The Determinants of Subjective Financial Satisfaction and the Moderating Roles of Gender and Marital Status. Family and Consumer Sciences Research Journal, 47(3), 237259.

Fujita, F., Diener, E., \& Sandvik, E. (1991). Gender differences in negative affect and well-being: the case for emotional intensity. Journal of Personality and Social Psychology, 61(3), 427-434.

Garrett, S., \& James III, R. N. (2013). Financial ratios and perceived household financial satisfaction. Journal of Financial Therapy, 4(1), 39-62.

Heller, D., Watson, D., \& Ilies, R. (2004). The role of person versus situation in life satisfaction: A critical examination. Psychological Bulletin, 130(4), 574-600.

Hori, M., \& Kamo, Y. (2018). Gender differences in happiness: The effects of marriage, social roles, and social support in East Asia. Applied Research in Quality of Life, 13(4), 839-857.

Hu, C. Y., \& Kamo, Y. (2007). The division of household labor in Taiwan. Journal of Comparative Family Studies, 38(1), 105-124.

Joo, S. H., \& Grable, J. E. (2004). An exploratory framework of the determinants of financial satisfaction. Journal of Family and Economic Issues, 25(1), 25-50.

Kaiser, H. F. (1974). An index of factorial simplicity. Psychometrika, 39, 32-36.

Krause, N. (1986). Stress and sex differences in depressive symptoms among older adults. Journal of Gerontology, 41, 727-731.

Laerd Statistics (2015). Principal components analysis (PCA) using SPSS Statistics. Statistical tutorials and software guides. Retrieved from https://statistics.laerd.com/

Loehlin, J. C., McCrae, R. R., Costa Jr, P. T., \& John, O. P. (1998). Heritabilities of common and measure-specific components of the Big Five personality factors. Journal of Research in Personality, 32(4), 431-453.

Lin, C. C., Cheng, T. C., \& Wang, S. C. (2014). Measuring subjective well-being in Taiwan. Social Indicators Research, 116(1), 17-45. 
Liu, F. (2017). Chinese young men's construction of exemplary masculinity: The hegemony of Chenggong. Men and Masculinities, 22(2), 294-316.

Lucas, R. E., \& Gohm, C. L. (2000). Age and sex differences in subjective well-being across cultures. Culture and Subjective Well-being , 3(2), 91-317.

Marley, C. S., Lerner, L. B., Panagopoulos, G., \& Kavaler, E. (2011). Personal, professional and financial satisfaction among American women urologists. International Brazillian Journal of Urology, $37(2), 187-194$.

McCrae, R. R., \& Terracciano, A. (2005). Universal features of personality traits from the observer's perspective: data from 50 cultures. Journal of Personality and Social Psychology, 88(3), 547-561.

Mendes de Leon, C. F., Rapp, S. S., \& Kasl, S. V. (1994). Financial strain and symptoms of depression in a community sample of elderly men and women. Journal of Aging and Health, 6, 448-468.

Netemeyer, R. G., Warmath, D., Fernandes, D., \& Lynch Jr, J. G. (2018). How am I doing? Perceived financial well-being, its potential antecedents, and its relation to overall well-being. Journal of Consumer Research, 45(1), 68-89.

Ng, W., \& Diener, E. (2014). What matters to the rich and the poor? Subjective well-being, financial satisfaction, and postmaterialist needs across the world. Journal of Personality and Social Psychology, 107(2), 326-338.

Radloff, L. S. (1977). The CES-D scale: A self report depression scale for research in the general population. Applied Psychological Measurements, 1, 385-401.

Seay, M., Asebedo, S., Thompson, C., Stueve, C., \& Russi, R. (2015). Mortgage holding and financial satisfaction in retirement. Journal of Financial Counseling and Planning, 26(2), 200-216.

Shek, D. T. (2006). Chinese family research: Puzzles, progress, paradigms, and policy implications. Journal of Family Issues, 27(3), 275-284.

Spielberger, C. D., Gorsuch, R. L., Lushene, R., Vagg, P. R., \& Jacobs, G. A. (1983). Consulting Psychologists Press; Palo Alto, CA: 1983. Manual for the state-trait anxiety inventory. 
Tharp, D. T. (2017). Three essays on personality characteristics and financial satisfaction. [Doctoral dissertation, Kansas State University]. K-State Research Exchange.

Tharp, D. T., Seay, M. C., Carswell, A. T., \& MacDonald, M. (2020). Big Five personality traits, dispositional affect, and financial satisfaction among older adults. Personality and Individual Differences, 166, 110211.

Tharp, D. T., Seay, M. C., Stueve, C., \& Anderson, S. (2020). Financial satisfaction and homeownership. Journal of Family and Economic Issues, 41, 255-280.

Thurstone, L. L. (1947). Multiple factor analysis. Chicago, IL: University of Chicago Press.

Tsou, M. W., \& Liu, J. T. (2001). Happiness and domain satisfaction in Taiwan. Journal of Happiness Studies, 2(3), 269-288.

UCLA: Statistical Consulting Group (n.d.). What happens if you omit the main effect in a regression model with an interaction? Retrieved from https://stats.idre.ucla.edu/stata/faq/what-happens-if-youomit-the-main-effect-in-a-regression-model-with-an-interaction/

Ware Jr, J. E., \& Sherbourne, C. D. (1992). The MOS 36-item short-form health survey (SF-36): I. Conceptual framework and item selection. Medical Care, 473-483.

Watson, D., \& Clark, L. A. (1992). On traits and temperament: General and specific factors of emotional experience and their relation to the five-factor model. Journal of Personality, 60(2), 441-476.

Watson, D., \& Clark, L. A. (1999). The PANAS-X: Manual for the positive and negative affect schedule - Expanded form. Unpublished manuscript. University of Iowa.

Watson, D., \& Walker, L. M. (1996). The long-term stability and predictive validity of trait measures of affect. Journal of Personality and Social Psychology, 70(3), 567-577. https://doi.org/10.1037/00223514.70.3.567

Williams, R. (2006). Generalized ordered logit/partial proportional odds models for ordinal dependent variables. The Stata Journal, 6(1), 58-82.

Williams, R. (2016). Understanding and interpreting generalized ordered logit models. The Journal of Mathematical Sociology, 40(1), 7-20. 
Woodyard, A. S., \& Robb, C. A. (2016). Consideration of Financial Satisfaction: What Consumers Know, Feel and Do from a Financial Perspective. Journal of Financial Therapy, 7(2), 41-61.

Wu, M. (2006). Hofstede's cultural dimensions 30 years later: A study of Taiwan and the United States. Intercultural Communication Studies, 15(1), 33-42.

Xiao, J. J., Chen, C., \& Chen, F. (2014). Consumer financial capability and financial satisfaction. Social Indicators Research, 118(1), 415-432.

Xiao, J. J., \& O'Neill, B. (2018). Propensity to plan, financial capability, and financial satisfaction. International Journal of Consumer Studies, 42(5), 501-512.

Xiao, J. J., \& Porto, N. (2017). Financial education and financial satisfaction: Financial literacy, behavior, and capability as mediators. International Journal of Bank Marketing, 35(5), 805-817.

Xu, X., \& Lai, S. C. (2002). Resources, gender ideologies, and marital power: The case of Taiwan. Journal of Family Issues, 23(2), 209-245.

Wu, J. S. Y. (2014). Continuity and change: Comparing work and care reconciliation of two generations of women in Taiwan. In Gender and Welfare States in East Asia (pp. 66-89). Palgrave Macmillan, London.

Yu, W. H. (2005). Changes in women's postmarital employment in Japan and Taiwan. Demography, 42(4), 693-717.

Yu, W. H. (2015). Women and employment in Taiwan: Taiwanese women's employment from a comparative perspective. https://www.brookings.edu/opinions/women-and-employment-intaiwan/.

Zhang, H. (2015). Wives' relative income and marital quality in Urban China: Gender role attitudes as a moderator. Journal of Comparative Family Studies, 46(2), 203-220.

Zuo, J. (2003). From revolutionary comrades to gendered partners: Marital construction of breadwinning in post-Mao urban China. Journal of Family Issues, 24(3), 314-337.

Zuckerman, M., Li, C., \& Diener, E. F. (2017). Societal conditions and the gender difference in wellbeing: Testing a three-stage model. Personality and Social Psychology Bulletin, 43(3), 329-336. 
Zyphur, M. J., Li, W. D., Zhang, Z., Arvey, R. D., \& Barsky, A. P. (2015). Income, personality, and subjective financial well-being: The role of gender in their genetic and environmental relationships. Frontiers in Psychology, 6, 1493. 
Figure 1. Integrative Model of Top-Down and Bottom-Up Predictors of Financial Satisfaction Moderated by Gender

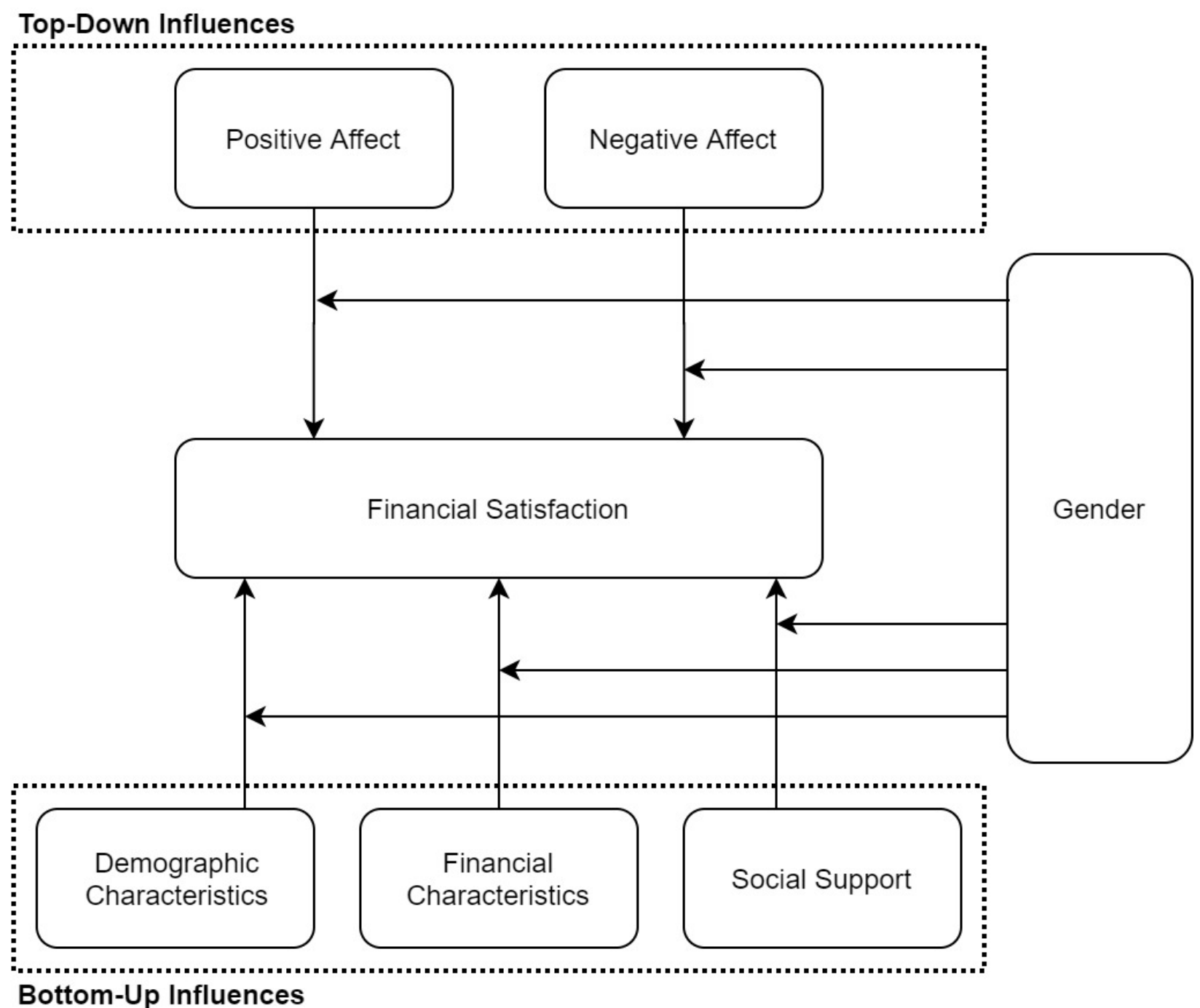


Figure 2. Variation in the Moderating Role of Gender on Top-Down and Bottom-Up Influences on Financial Satisfaction by Social Context

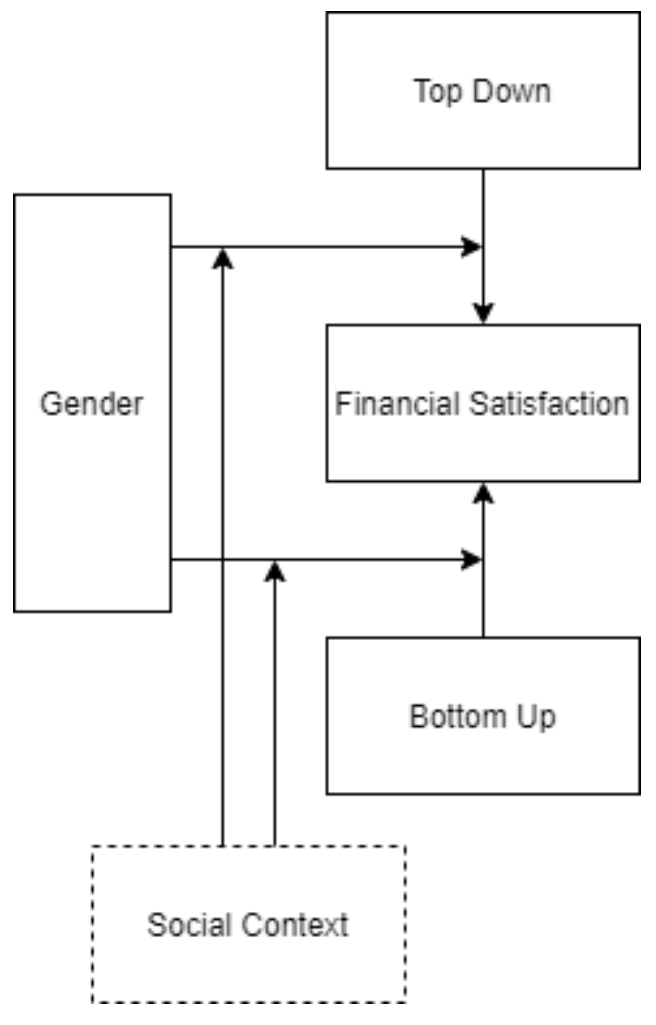


Figure 3. Varying Social Context for Gender Roles by Marriage and Employment Status Outside of the Household

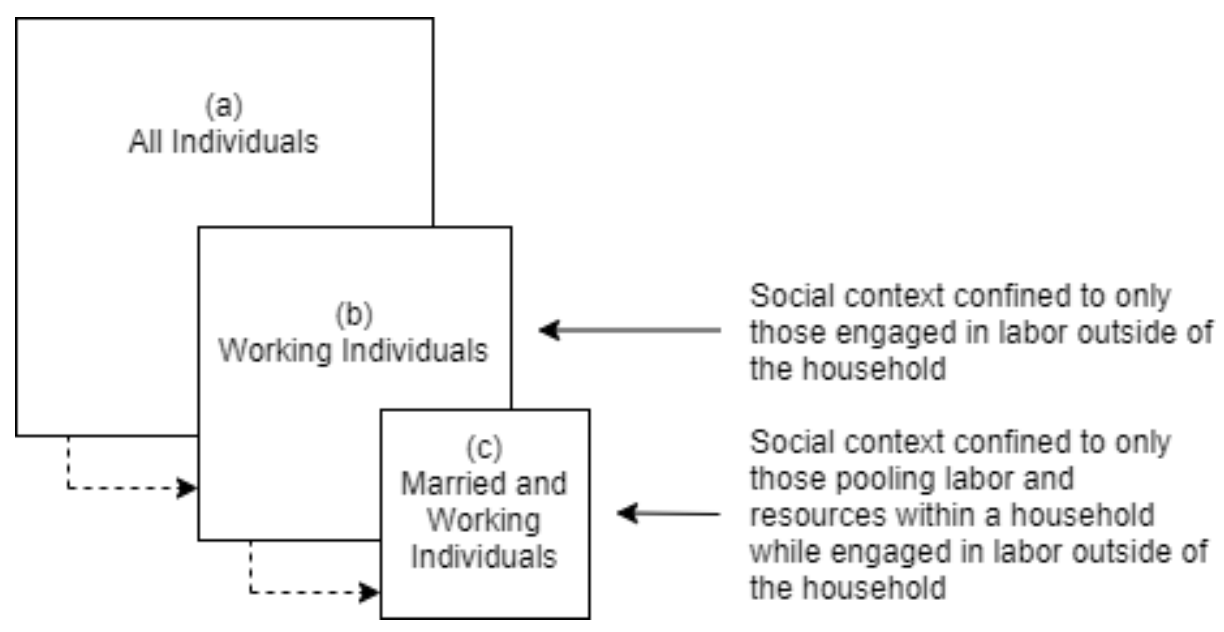


Figure 4. Visual Summary of Relationships and Gender Differences Observed by Social Context

\section{Sample 1: All Respondents}

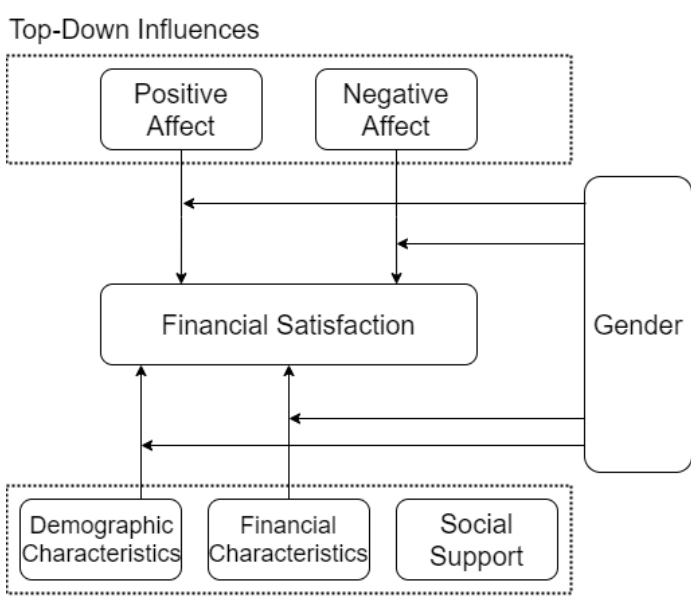

Bottom-Up Influences

\section{Sample 2: Working Individuals}

Top-Down Influences

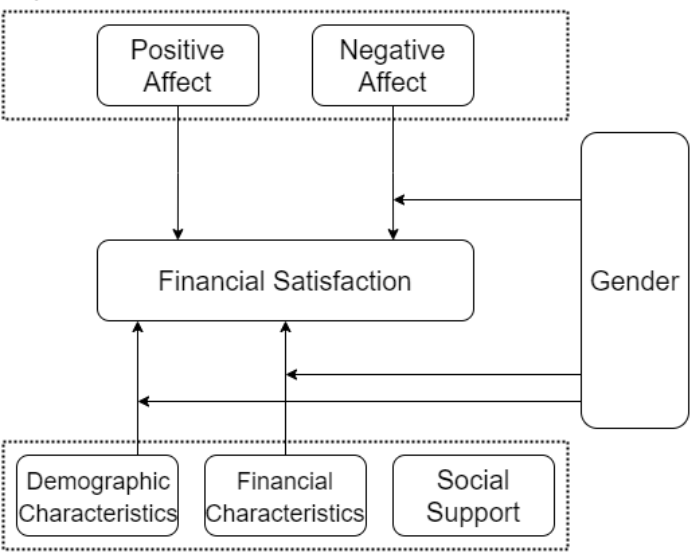

Bottom-Up Influences
Sample 3: Married and Working Individuals

Top-Down Influences

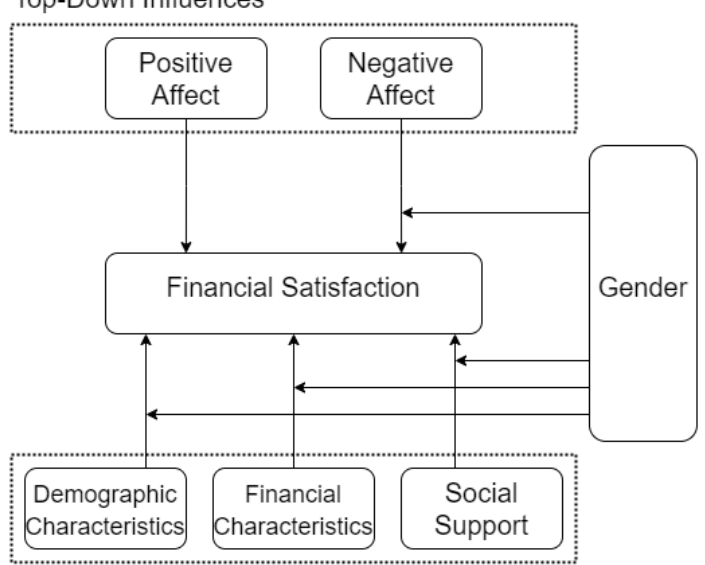

Bottom-Up Influences 
Table 1. Descriptive Statistics

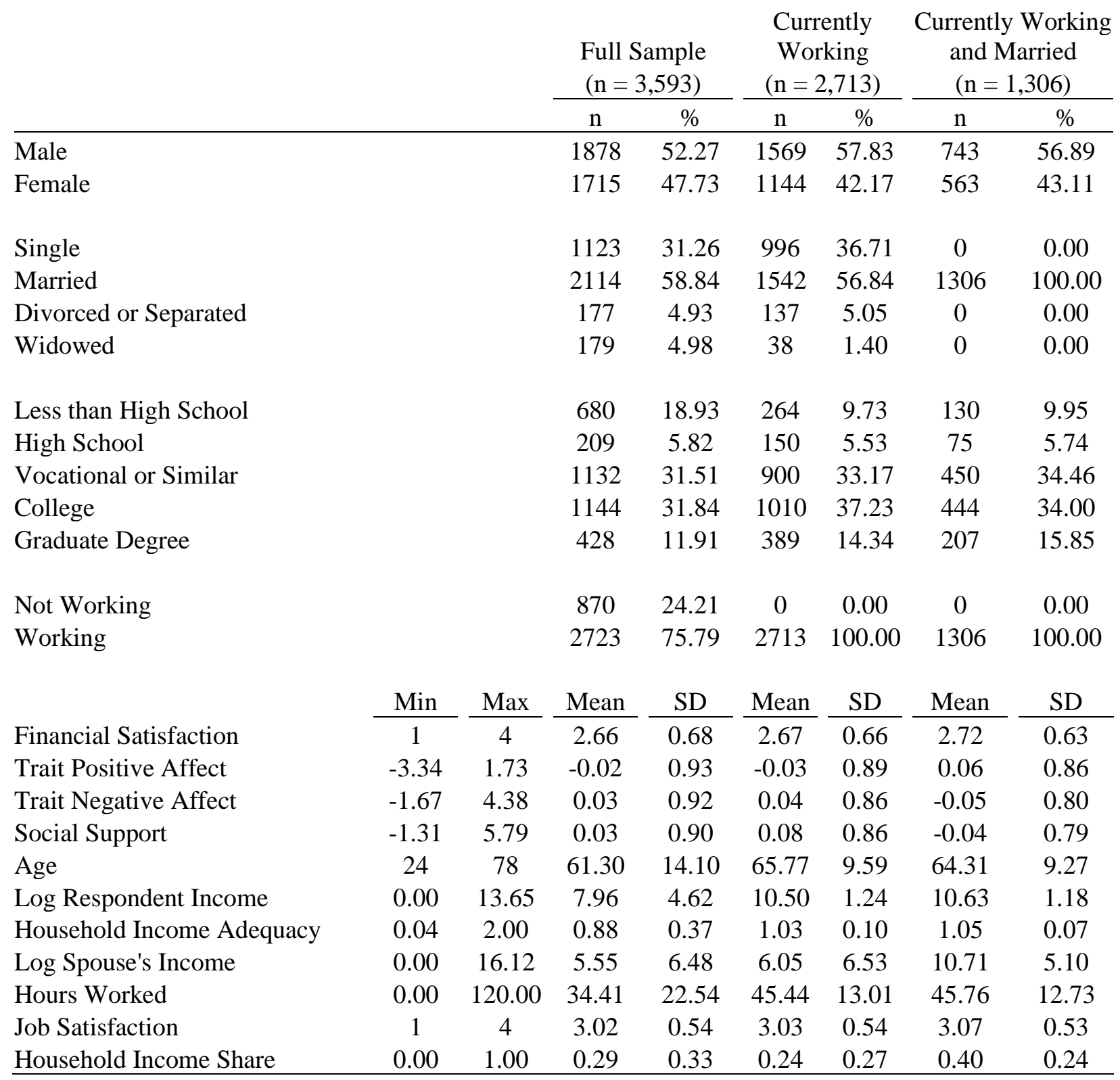


Table 2. Rotated Factor Scores from Exploratory Factor Analysis

$\begin{array}{lll}\text { Factor } 1 & \text { Factor } 2 & \text { Factor } 3\end{array}$

\begin{tabular}{lccc} 
Feeling & Trait Positive Affect & Trait Negative Affect & Social Support \\
\hline At ease & 0.933 & & \\
Calm & 0.848 & & \\
Safe & 0.784 & & \\
Happy & 0.721 & & \\
Depressed & & 0.754 & \\
Cannot overcome obstacles & & 0.744 & \\
Worried & & 0.730 & \\
Nothing can make you happy & 0.671 & 0.932 \\
Nervous & 0.657 & 0.845 \\
That others do not like you & & & 0.416 \\
That others are not friendly & & & \\
Lonely & & & \\
\hline
\end{tabular}

Note: Exploratory factor analysis (EFA) conducted with Promax rotation with Kaiser normalization. Component loadings of less than 0.3 have been excluded from the table above. Interpretations of each component have been provided in column headers. 
Table 3. Average Marginal Effects from Generalized Ordered Logistic Regressions Among Full Sample

\begin{tabular}{|c|c|c|c|c|c|c|c|c|}
\hline \multirow[b]{2}{*}{ Variable } & \multicolumn{2}{|c|}{$\begin{array}{c}\text { Outcome } 1 \\
\text { Very Dissatisfied } \\
\text { Marginal Effect / Sig } \\
\text { (Std. Error) }\end{array}$} & \multicolumn{2}{|c|}{$\begin{array}{c}\text { Outcome } 2 \\
\text { Somewhat Dissatisfied } \\
\text { Marginal Effect / Sig } \\
\text { (Std. Error) }\end{array}$} & \multicolumn{2}{|c|}{$\begin{array}{c}\text { Outcome } 3 \\
\text { Somewhat Satisfied } \\
\text { Marginal Effect / Sig } \\
\text { (Std. Error) }\end{array}$} & \multicolumn{2}{|c|}{$\begin{array}{c}\text { Outcome } 4 \\
\text { Very Satisfied } \\
\text { Marginal Effect / Sig } \\
\text { (Std. Error) }\end{array}$} \\
\hline & Male & Female & Male & Female & Male & Female & Male & Female \\
\hline \multicolumn{9}{|l|}{ Top-Down Factors } \\
\hline Trait Positive Affect & $\begin{array}{l}-0.029 * * * \\
(0.005)\end{array}$ & $\begin{array}{l}-0.027 * * * \\
(0.003)\end{array}$ & $\begin{array}{l}-0.094 * * * \\
(0.011)\end{array}$ & $\begin{array}{l}-0.078 * * * \\
(0.009)\end{array}$ & $\begin{array}{r}0.030 \\
(0.021)\end{array}$ & $\begin{array}{l}0.066^{* * * *} \\
(0.006)\end{array}$ & $\begin{array}{l}0.092 * * * \\
(0.019)\end{array}$ & $\begin{array}{l}0.039 * * * \\
(0.007)\end{array}$ \\
\hline Trait Negative Affect & $\begin{array}{c}0.023 * \\
(0.009)\end{array}$ & $\begin{array}{l}0.020^{* * * *} \\
(0.006)\end{array}$ & $\begin{array}{r}0.012 \\
(0.017)\end{array}$ & $\begin{array}{l}0.044 * * * \\
(0.011)\end{array}$ & $\begin{array}{l}-0.047 * \\
(0.019)\end{array}$ & $\begin{array}{l}-0.050 * * * \\
(0.013)\end{array}$ & $\begin{array}{r}0.012 \\
(0.011)\end{array}$ & $\begin{array}{l}-0.014 * * * \\
(0.003)\end{array}$ \\
\hline \multicolumn{9}{|l|}{ Bottom-Up Factors } \\
\hline Age & $\begin{array}{r}0.033 \\
(0.039)\end{array}$ & $\begin{array}{r}0.048 \\
(0.044)\end{array}$ & $\begin{array}{r}0.072 \\
(0.071)\end{array}$ & $\begin{array}{r}0.088 \\
(0.061)\end{array}$ & $\begin{array}{l}-0.084 \\
(0.094)\end{array}$ & $\begin{array}{l}-0.110 \\
(0.091)\end{array}$ & $\begin{array}{r}-0.020 \\
(0.016)\end{array}$ & $\begin{array}{l}-0.026 \dagger \\
(0.014)\end{array}$ \\
\hline Age squared & $\begin{array}{r}-0.009 \\
(0.023)\end{array}$ & $\begin{array}{r}-0.017 \\
(0.021)\end{array}$ & $\begin{array}{r}-0.026 \\
(0.069)\end{array}$ & $\begin{array}{r}-0.045 \\
(0.062)\end{array}$ & $\begin{array}{r}0.025 \\
(0.065)\end{array}$ & $\begin{array}{r}0.042 \\
(0.051)\end{array}$ & $\begin{array}{r}0.009 \\
(0.027)\end{array}$ & $\begin{array}{r}0.020 \\
(0.032)\end{array}$ \\
\hline \multicolumn{9}{|l|}{ Marital Status } \\
\hline Married vs. Divorced & $\begin{array}{l}-0.042 * \\
(0.017)\end{array}$ & $\begin{array}{r}-0.024 \\
(0.016)\end{array}$ & $\begin{array}{l}-0.090 * * \\
(0.030)\end{array}$ & $\begin{array}{l}-0.052 \dagger \\
(0.030)\end{array}$ & $\begin{array}{l}0.109 * * \\
(0.041)\end{array}$ & $\begin{array}{r}0.059 \\
(0.038)\end{array}$ & $\begin{array}{l}0.024 * * * \\
(0.007)\end{array}$ & $\begin{array}{l}0.017 \dagger \\
(0.009)\end{array}$ \\
\hline Single vs. Divorced & $\begin{array}{l}-0.046 * * \\
(0.018)\end{array}$ & $\begin{array}{r}-0.020 \\
(0.017)\end{array}$ & $\begin{array}{l}-0.101 * * \\
(0.031)\end{array}$ & $\begin{array}{r}-0.043 \\
(0.033)\end{array}$ & $\begin{array}{l}0.119 * * \\
(0.041)\end{array}$ & $\begin{array}{r}0.050 \\
(0.040)\end{array}$ & $\begin{array}{l}0.028^{* * *} \\
(0.008)\end{array}$ & $\begin{array}{r}0.014 \\
(0.010)\end{array}$ \\
\hline \multicolumn{9}{|l|}{ Education } \\
\hline Graduate vs. College & $\begin{array}{r}0.011 \\
(0.013)\end{array}$ & $\begin{array}{l}-0.009 \\
(0.018)\end{array}$ & $\begin{array}{r}-0.028 \\
(0.026)\end{array}$ & $\begin{array}{r}-0.050 \\
(0.038)\end{array}$ & $\begin{array}{r}0.044 \\
(0.029)\end{array}$ & $\begin{array}{l}-0.029 \\
(0.045)\end{array}$ & $\begin{array}{l}-0.026^{*} \\
(0.013)\end{array}$ & $\begin{array}{l}0.088^{* *} \\
(0.032)\end{array}$ \\
\hline Less than High School vs. College & $\begin{array}{r}0.019 \\
(0.015)\end{array}$ & $\begin{array}{l}0.051^{* *} \\
(0.018)\end{array}$ & $\begin{array}{r}-0.009 \\
(0.031)\end{array}$ & $\begin{array}{r}-0.029 \\
(0.032)\end{array}$ & $\begin{array}{r}0.022 \\
(0.034)\end{array}$ & $\begin{array}{r}0.008 \\
(0.037)\end{array}$ & $\begin{array}{l}-0.032 * \\
(0.014)\end{array}$ & $\begin{array}{l}-0.030 \dagger \\
(0.016)\end{array}$ \\
\hline Vocational vs. College & $\begin{array}{r}0.014 \\
(0.012)\end{array}$ & $\begin{array}{c}0.032 * \\
(0.013)\end{array}$ & $\begin{array}{r}-0.021 \\
(0.024)\end{array}$ & $\begin{array}{l}-0.062 * \\
(0.025)\end{array}$ & $\begin{array}{r}0.036 \\
(0.025)\end{array}$ & $\begin{array}{l}0.049 \dagger \\
(0.028)\end{array}$ & $\begin{array}{l}-0.029 * \\
(0.012)\end{array}$ & $\begin{array}{l}-0.019 \\
(0.015)\end{array}$ \\
\hline High School vs. Graduate & $\begin{array}{r}0.000 \\
(0.013)\end{array}$ & $\begin{array}{c}0.043 \dagger \\
(0.023)\end{array}$ & $\begin{array}{r}0.000 \\
(0.032)\end{array}$ & $\begin{array}{r}-0.007 \\
(0.045)\end{array}$ & $\begin{array}{r}0.000 \\
(0.035)\end{array}$ & $\begin{array}{r}0.073 \\
(0.054)\end{array}$ & $\begin{array}{r}0.000 \\
(0.010)\end{array}$ & $\begin{array}{l}-0.108^{* * *} \\
(0.033)\end{array}$ \\
\hline Less than High School vs. Graduate & $\begin{array}{r}0.008 \\
(0.012)\end{array}$ & $\begin{array}{l}0.059 * * \\
(0.022)\end{array}$ & $\begin{array}{r}0.019 \\
(0.029)\end{array}$ & $\begin{array}{r}0.021 \\
(0.042)\end{array}$ & $\begin{array}{r}-0.021 \\
(0.033)\end{array}$ & $\begin{array}{r}0.037 \\
(0.050)\end{array}$ & $\begin{array}{r}-0.006 \\
(0.009)\end{array}$ & $\begin{array}{l}-0.117 * * * \\
(0.033)\end{array}$ \\
\hline
\end{tabular}


Vocation vs. Graduate

Financial Factors

Log Respondent Income

Household Income Adequacy

Work Status

Working vs. Not Working

Social Factor

Social Support

\begin{abstract}
0.003
\end{abstract}
$(0.009)$

$-0.019$

$(0.022)$

$-0.001$

(0.005)

$-0.019$

$(0.078)$
$0.040 *$

(0.018)

0.007

(0.021)

$-0.011$

$(0.037)$

-0.008
$(0.023)$

$0.078 \dagger$

(0.045)

$-0.002$

$(0.007)$

$-0.107 * * *$

$-0.022 * *$

$-0.151 * * *$

-0.057 *

$(0.040)$

$(0.024)$

(0.008)

$-0.001$

(0.004)

$-0.003$

$(0.024)$

$-0.242$

$(0.155)$

0.070 **

$0.412 * *$

$(0.032)$

(0.014)

$(0.010)$

0.003

$(0.022)$

(0.156)

0.009

$0.244 *$

$0.041 \dagger$
$(0.022)$

(0.098)

0.097 *

$(0.014)$

0.003

0.001

(0.012)

$(0.010)$

(0.005)

0.001

(0.004)

\begin{tabular}{|c|c|c|c|c|c|c|c|c|}
\hline Social Support & $\begin{array}{r}-0.002 \\
(0.003) \\
\end{array}$ & $\begin{array}{r}-0.003 \\
(0.004) \\
\end{array}$ & $\begin{array}{r}-0.006 \\
(0.009) \\
\end{array}$ & $\begin{array}{r}-0.007 \\
(0.009) \\
\end{array}$ & $\begin{array}{r}0.007 \\
(0.010) \\
\end{array}$ & $\begin{array}{r}0.007 \\
(0.009) \\
\end{array}$ & $\begin{array}{r}0.002 \\
(0.003) \\
\end{array}$ & $\begin{array}{r}0.003 \\
(0.003) \\
\end{array}$ \\
\hline & Male & Female & & & & & & \\
\hline $\mathrm{N}$ & 1,878 & 1,715 & & & & & & \\
\hline Pseudo $\mathrm{R}^{2}$ & 0.114 & 0.111 & & & & & & \\
\hline LR $\chi 2$ (d.f.) & $425.34(25)^{* * *}$ & $375.93(21) * * *$ & & & & & & \\
\hline
\end{tabular}

\section{LR $\chi^{2}$ (d.f.)}

$425.34(25) * * * \quad 375.93(21)^{* * *}$ operationalized using a Likert-type scale from 1 (very dissatisfied) to 4 (very satisfied). Average marginal effects for continuous variables are reported based on one standard deviation changes in independent variables across the entire sample to standardize changes between genders. Independent variables include natural log of respondent income, household income adequacy (natural log of total household income divided by natural log of total household expenses), a binary variable of working status (working or not), age, age squared, a categorical variable of respondent marital status (single, married, divorced or separated, widowed), a categorical variable of highest education attained (less than high school, high school, vocational or similar college, college, and graduate degree), and three factors generated via principal components analysis: positive affect, negative affect, and social support. For brevity, results from the marital status and education variables are only included if a marginal effect for a given characteristic was significant a level of $p<.05$.

$* * * p<.001, * * p<.01, * p<.05, \dagger p<.1$ 
Table 4. Average Marginal Effects from Generalized Ordered Logistic Regression Among Working Individuals

\begin{tabular}{|c|c|c|c|c|c|c|c|c|}
\hline \multirow[b]{2}{*}{ Variable } & \multicolumn{2}{|c|}{$\begin{array}{c}\text { Outcome } 1 \\
\text { Very Dissatisfied } \\
\text { Marginal Effect / Sig } \\
\text { (Std. Error) }\end{array}$} & \multicolumn{2}{|c|}{$\begin{array}{c}\text { Outcome } 2 \\
\text { Somewhat Dissatisfied } \\
\text { Marginal Effect / Sig } \\
\text { (Std. Error) }\end{array}$} & \multicolumn{2}{|c|}{$\begin{array}{c}\text { Outcome } 3 \\
\text { Somewhat Satisfied } \\
\text { Marginal Effect / Sig } \\
\text { (Std. Error) }\end{array}$} & \multicolumn{2}{|c|}{$\begin{array}{c}\text { Outcome } 4 \\
\text { Very Satisfied } \\
\text { Marginal Effect / Sig } \\
\text { (Std. Error) }\end{array}$} \\
\hline & Male & Female & Male & Female & Male & Female & Male & Female \\
\hline \multicolumn{9}{|l|}{ Top-Down Factors } \\
\hline Trait Positive Affect & $\begin{array}{l}-0.021 * * * \\
(0.003)\end{array}$ & $\begin{array}{l}-0.017 * * * \\
(0.004)\end{array}$ & $\begin{array}{l}-0.078 * * * \\
(0.009)\end{array}$ & $\begin{array}{l}-0.055^{* * *} \\
(0.012)\end{array}$ & $\begin{array}{l}0.065^{* * *} \\
(0.007)\end{array}$ & $\begin{array}{l}0.053 * * * \\
(0.011)\end{array}$ & $\begin{array}{l}0.033 * * * \\
(0.006)\end{array}$ & $\begin{array}{l}0.018 * * * \\
(0.005)\end{array}$ \\
\hline Trait Negative Affect & $\begin{array}{r}0.003 \\
(0.004)\end{array}$ & $\begin{array}{l}0.018 * * \\
(0.006)\end{array}$ & $\begin{array}{r}0.009 \\
(0.013)\end{array}$ & $\begin{array}{l}0.045^{* *} \\
(0.014)\end{array}$ & $\begin{array}{r}-0.009 \\
(0.013)\end{array}$ & $\begin{array}{l}-0.051 * * \\
(0.017)\end{array}$ & $\begin{array}{r}-0.003 \\
(0.004)\end{array}$ & $\begin{array}{l}-0.011^{* *} \\
(0.003)\end{array}$ \\
\hline $\begin{array}{l}\text { Bottom-Up Factors } \\
\text { Demographic Factors }\end{array}$ & & & & & & & & \\
\hline Age & $\begin{array}{r}-0.002 \\
(0.024)\end{array}$ & $\begin{array}{r}0.074 \\
(0.066)\end{array}$ & $\begin{array}{r}-0.007 \\
(0.077)\end{array}$ & $\begin{array}{l}0.138 \dagger \\
(0.075)\end{array}$ & $\begin{array}{r}0.007 \\
(0.075)\end{array}$ & $\begin{array}{r}-0.183 \\
(0.128)\end{array}$ & $\begin{array}{r}0.002 \\
(0.026)\end{array}$ & $\begin{array}{l}-0.028 * \\
(0.012)\end{array}$ \\
\hline Age Squared & $\begin{array}{r}0.015 \\
(0.031)\end{array}$ & $\begin{array}{l}-0.030 \dagger \\
(0.017)\end{array}$ & $\begin{array}{r}0.042 \\
(0.079)\end{array}$ & $\begin{array}{r}-0.110 \\
(0.073)\end{array}$ & $\begin{array}{r}-0.044 \\
(0.089)\end{array}$ & $\begin{array}{c}0.094 * \\
(0.043)\end{array}$ & $\begin{array}{r}-0.012 \\
(0.021)\end{array}$ & $\begin{array}{r}0.047 \\
(0.047)\end{array}$ \\
\hline \multicolumn{9}{|l|}{ Marital Status } \\
\hline Married vs. Divorced & $\begin{array}{l}-0.036^{*} \\
(0.018)\end{array}$ & $\begin{array}{l}-0.033 \dagger \\
(0.019)\end{array}$ & $\begin{array}{c}-0.086^{*} \\
(0.035)\end{array}$ & $\begin{array}{l}-0.080 * \\
(0.037)\end{array}$ & $\begin{array}{c}0.100 * \\
(0.045)\end{array}$ & $\begin{array}{c}0.095^{*} \\
(0.048)\end{array}$ & $\begin{array}{l}0.022 * * \\
(0.008)\end{array}$ & $\begin{array}{c}0.018 * \\
(0.008)\end{array}$ \\
\hline Single vs. Divorced & $\begin{array}{l}-0.045^{*} \\
(0.018)\end{array}$ & $\begin{array}{l}-0.033 \dagger \\
(0.019)\end{array}$ & $\begin{array}{l}-0.117 * * \\
(0.036)\end{array}$ & $\begin{array}{l}-0.078 * \\
(0.040)\end{array}$ & $\begin{array}{l}0.129 * * \\
(0.045)\end{array}$ & $\begin{array}{c}0.093 \dagger \\
(0.051)\end{array}$ & $\begin{array}{l}0.032 * * * \\
(0.009)\end{array}$ & $\begin{array}{c}0.018 * \\
(0.008)\end{array}$ \\
\hline Widowed vs. Divorced & $\begin{array}{r}-0.025 \\
(0.047)\end{array}$ & $\begin{array}{l}-0.053^{*} \\
(0.023)\end{array}$ & $\begin{array}{l}-0.056 \\
(0.120)\end{array}$ & $\begin{array}{l}-0.148^{*} \\
(0.064)\end{array}$ & $\begin{array}{r}0.068 \\
(0.136)\end{array}$ & $\begin{array}{c}0.158^{*} \\
(0.063)\end{array}$ & $\begin{array}{r}0.013 \\
(0.031)\end{array}$ & $\begin{array}{c}0.043 \dagger \\
(0.025)\end{array}$ \\
\hline Single vs. Married & $\begin{array}{l}-0.009 \dagger \\
(0.005)\end{array}$ & $\begin{array}{r}0.001 \\
(0.007)\end{array}$ & $\begin{array}{l}-0.031 \dagger \\
(0.017)\end{array}$ & $\begin{array}{r}0.002 \\
(0.021)\end{array}$ & $\begin{array}{l}0.029 \dagger \\
(0.017)\end{array}$ & $\begin{array}{r}-0.002 \\
(0.022)\end{array}$ & $\begin{array}{c}0.010 \dagger \\
(0.006)\end{array}$ & $\begin{array}{r}-0.001 \\
(0.006)\end{array}$ \\
\hline \multicolumn{9}{|l|}{ Education } \\
\hline Graduate vs. College & $\begin{array}{r}0.001 \\
(0.012)\end{array}$ & $\begin{array}{l}-0.031 * \\
(0.015)\end{array}$ & $\begin{array}{r}-0.023 \\
(0.028)\end{array}$ & $\begin{array}{r}-0.028 \\
(0.040)\end{array}$ & $\begin{array}{c}0.054 \dagger \\
(0.030)\end{array}$ & $\begin{array}{r}-0.014 \\
(0.044)\end{array}$ & $\begin{array}{l}-0.032 * \\
(0.014)\end{array}$ & $\begin{array}{l}0.073 * * \\
(0.025)\end{array}$ \\
\hline High School vs. College & $\begin{array}{r}-0.007 \\
(0.013)\end{array}$ & $\begin{array}{r}0.008 \\
(0.015)\end{array}$ & $\begin{array}{r}-0.047 \\
(0.036)\end{array}$ & $\begin{array}{r}0.023 \\
(0.045)\end{array}$ & $\begin{array}{c}0.078 * \\
(0.036)\end{array}$ & $\begin{array}{r}-0.026 \\
(0.051)\end{array}$ & $\begin{array}{r}-0.024 \\
(0.017)\end{array}$ & $\begin{array}{r}-0.005 \\
(0.010)\end{array}$ \\
\hline Less Than High School vs. College & $\begin{array}{r}0.010 \\
(0.015)\end{array}$ & $\begin{array}{l}0.107^{* *} \\
(0.039)\end{array}$ & $\begin{array}{r}0.007 \\
(0.036)\end{array}$ & $\begin{array}{r}-0.031 \\
(0.048)\end{array}$ & $\begin{array}{r}0.023 \\
(0.039)\end{array}$ & $\begin{array}{r}-0.069 \\
(0.056)\end{array}$ & $\begin{array}{l}-0.040^{* *} \\
(0.014)\end{array}$ & $\begin{array}{r}-0.007 \\
(0.017)\end{array}$ \\
\hline
\end{tabular}


Vocational vs. College

High School vs. Graduate

Less Than High School vs. Graduate

Vocational vs. Graduate

Less Than High School vs. High School

Vocational vs. Less Than High School

Financial Factors

Log Respondent Income

Household Income Adequacy

Hours Worked

Job Satisfaction

\section{Social Factor}

Social Support

0.006
$(0.012)$
-0.007
$(0.010)$
0.010
$(0.012)$
0.006
$(0.007)$
0.017
$(0.013)$
-0.004
$(0.011)$

0.000

(0.007)

$0.039 \dagger$

(0.021)

$0.138^{* * *}$

(0.041)

$0.031 *$

(0.016)

$0.100 *$

$(0.041)$

(0.039)

$-0.009^{* *}$

(0.003)

$-0.001$

$(0.003)$

$0.012 *$

(0.005)

$-0.020 * * *$

(0.003)

$-0.001$

$(0.003)$

$-0.009 * *$

$(0.003)$

0.006

(0.006)

$-0.018^{* * *}$

(0.004)
$-0.108 * *$

$-0.005$

(0.025)

$-0.025$

$(0.036)$

0.030

(0.036)

0.017

$(0.023)$

0.054

(0.040)

$-0.012$

(0.030)

$-0.031^{* *}$

$(0.012)$

$-0.003$

(0.009)

$-0.020^{*}$

$(0.010)$

$-0.077 * *$

(0.010)

$-0.001$

-0.001
$(0.003)$

$-0.005$

$-0.002$

(0.011)

$\mathrm{N}$

\begin{tabular}{|c|c|}
\hline Male & Female \\
\hline 1,569 & 1,144 \\
\hline 0.136 & 0.130 \\
\hline
\end{tabular}

\section{Pseudo $\mathrm{R}^{2}$}

0.136

0.130

$410.42(22) * * * 285.34(24) * * *$

Notes: This table includes the results from two generalized ordered logistic regressions (partial proportional odds models) predicting financial satisfaction operationalized using a Likert-type scale from 1 (very dissatisfied) to 4 (very satisfied). Average marginal effects for continuous variables are reported based on one standard deviation changes in independent variables across the entire sample to standardize changes between genders. Independent variables include a categorical variable of respondent marital status (single, married, divorced or separated, widowed), a categorical variable of highest education attained (less than high school, high school, vocational or similar college, college, and graduate degree), natural log of respondent income, hou sehold income adequacy (natural log 
of total household income divided by natural log of total household expenses), age, age squared, average hours worked per week, job satisfaction (ordinal measure on a four-point Likert-type scale from very dissatisfied to very satisfied treated as a continuous variable), and three factors generated via exploratory factor analysis: positive affect, negative affect, and social support. For brevity, results from the marital status and education variables are only included if a marginal effect for that variable was significant a level of $p<.05$.

$* * * p<.001, * * p<.01, * p<.05, \dagger p<.1$ 
Table 5. Average Marginal Effects from Generalized Ordered Logistic Regression Among Individuals Married and Working

\begin{tabular}{|c|c|c|c|c|c|c|c|c|}
\hline \multirow[b]{2}{*}{ Variable } & \multicolumn{2}{|c|}{$\begin{array}{c}\text { Outcome } 1 \\
\text { Very Dissatisfied } \\
\text { Marginal Effect / Sig } \\
\quad \text { (Std. Error) }\end{array}$} & \multicolumn{2}{|c|}{$\begin{array}{c}\text { Outcome } 2 \\
\text { Somewhat Dissatisfied } \\
\text { Marginal Effect / Sig } \\
\text { (Std. Error) }\end{array}$} & \multicolumn{2}{|c|}{$\begin{array}{c}\text { Outcome } 3 \\
\text { Somewhat Satisfied } \\
\text { Marginal Effect / Sig } \\
\text { (Std. Error) }\end{array}$} & \multicolumn{2}{|c|}{$\begin{array}{c}\text { Outcome } 4 \\
\text { Very Satisfied } \\
\text { Marginal Effect / Sig } \\
\text { (Std. Error) }\end{array}$} \\
\hline & Male & Female & Male & Female & Male & Female & Male & Female \\
\hline \multicolumn{9}{|l|}{ Top-Down Factors } \\
\hline Positive Affect & $\begin{array}{l}-0.016^{* * * *} \\
(0.003)\end{array}$ & $\begin{array}{l}-0.013 * * \\
(0.004)\end{array}$ & $\begin{array}{l}-0.074 * * * \\
(0.012)\end{array}$ & $\begin{array}{l}-0.058 * * * \\
(0.018)\end{array}$ & $\begin{array}{l}0.047 * * * \\
(0.007)\end{array}$ & $\begin{array}{l}0.052^{* * *} \\
(0.014)\end{array}$ & $\begin{array}{l}0.042^{* * * *} \\
(0.010)\end{array}$ & $\begin{array}{c}0.019 * \\
(0.008)\end{array}$ \\
\hline Negative Affect & $\begin{array}{r}-0.002 \\
(0.004)\end{array}$ & $\begin{array}{r}0.008 \\
(0.007)\end{array}$ & $\begin{array}{r}-0.006 \\
(0.017)\end{array}$ & $\begin{array}{r}0.027 \\
(0.022)\end{array}$ & $\begin{array}{r}0.005 \\
(0.014)\end{array}$ & $\begin{array}{l}-0.028 \\
(0.023)\end{array}$ & $\begin{array}{r}0.003 \\
(0.008)\end{array}$ & $\begin{array}{r}-0.007 \\
(0.005)\end{array}$ \\
\hline \multicolumn{9}{|l|}{ Bottom-Up Factors } \\
\hline Age & $\begin{array}{r}0.003 \\
(0.030)\end{array}$ & $\begin{array}{r}0.155 \\
(0.190)\end{array}$ & $\begin{array}{r}0.013 \\
(0.117)\end{array}$ & $\begin{array}{l}0.226 * * * \\
(0.061)\end{array}$ & $\begin{array}{l}-0.011 \\
(0.102)\end{array}$ & $\begin{array}{r}-0.340 \\
(0.232)\end{array}$ & $\begin{array}{l}-0.005 \\
(0.045)\end{array}$ & $\begin{array}{l}-0.040 * * \\
(0.013)\end{array}$ \\
\hline Age Squared & $\begin{array}{r}0.008 \\
(0.033)\end{array}$ & $\begin{array}{l}-0.032 * \\
(0.014)\end{array}$ & $\begin{array}{r}0.027 \\
(0.119)\end{array}$ & $\begin{array}{l}-0.174 \dagger \\
(0.101)\end{array}$ & $\begin{array}{r}-0.030 \\
(0.106)\end{array}$ & $\begin{array}{l}0.106 * * * \\
(0.021)\end{array}$ & $\begin{array}{r}-0.005 \\
(0.046)\end{array}$ & $\begin{array}{r}0.100 \\
(0.124)\end{array}$ \\
\hline \multicolumn{9}{|l|}{ Financial Factors } \\
\hline Log Respondent Income & $\begin{array}{l}-0.016^{* *} \\
(0.005)\end{array}$ & $\begin{array}{r}-0.002 \\
(0.003)\end{array}$ & $\begin{array}{l}-0.073 * * \\
(0.025)\end{array}$ & $\begin{array}{r}-0.009 \\
(0.013)\end{array}$ & $\begin{array}{l}0.047 * * * \\
(0.012)\end{array}$ & $\begin{array}{r}0.009 \\
(0.013)\end{array}$ & $\begin{array}{c}0.041^{*} \\
(0.020)\end{array}$ & $\begin{array}{r}0.003 \\
(0.004)\end{array}$ \\
\hline Log Spouse Income & $\begin{array}{l}-0.004 \\
(0.005)\end{array}$ & $\begin{array}{r}-0.002 \\
(0.011)\end{array}$ & $\begin{array}{l}-0.018 \\
(0.020)\end{array}$ & $\begin{array}{l}-0.007 \\
(0.042)\end{array}$ & $\begin{array}{r}0.014 \\
(0.015)\end{array}$ & $\begin{array}{r}0.006 \\
(0.040)\end{array}$ & $\begin{array}{r}0.008 \\
(0.010)\end{array}$ & $\begin{array}{r}0.002 \\
(0.012)\end{array}$ \\
\hline Household Income Share & $\begin{array}{l}-0.015^{*} \\
(0.007)\end{array}$ & $\begin{array}{r}-0.010 \\
(0.007)\end{array}$ & $\begin{array}{r}0.035 \\
(0.034)\end{array}$ & $\begin{array}{r}-0.044 \\
(0.031)\end{array}$ & $\begin{array}{l}-0.010 \\
(0.031)\end{array}$ & $\begin{array}{r}0.040 \\
(0.026)\end{array}$ & $\begin{array}{r}-0.011 \\
(0.013)\end{array}$ & $\begin{array}{r}0.014 \\
(0.012)\end{array}$ \\
\hline Household Income Adequacy & $\begin{array}{l}-0.007 * \\
(0.003)\end{array}$ & $\begin{array}{r}0.009 \\
(0.007)\end{array}$ & $\begin{array}{l}-0.029 * \\
(0.012)\end{array}$ & $\begin{array}{l}-0.081 * * * \\
(0.024)\end{array}$ & $\begin{array}{l}0.022^{* * *} \\
(0.009)\end{array}$ & $\begin{array}{l}0.075^{* *} \\
(0.026)\end{array}$ & $\begin{array}{c}0.014 * \\
(0.006)\end{array}$ & $\begin{array}{r}-0.003 \\
(0.010)\end{array}$ \\
\hline Hours Worked & $\begin{array}{l}0.011 \dagger \\
(0.006)\end{array}$ & $\begin{array}{r}0.007 \\
(0.007)\end{array}$ & $\begin{array}{r}-0.017 \\
(0.013)\end{array}$ & $\begin{array}{l}-0.039 * \\
(0.015)\end{array}$ & $\begin{array}{r}-0.004 \\
(0.017)\end{array}$ & $\begin{array}{c}0.045^{*} \\
(0.019)\end{array}$ & $\begin{array}{r}0.009 \\
(0.010)\end{array}$ & $\begin{array}{l}-0.014 \dagger \\
(0.008)\end{array}$ \\
\hline Job Satisfaction & $\begin{array}{l}-0.016 \text { *** } \\
(0.003)\end{array}$ & $\begin{array}{l}-0.016^{* * *} \\
(0.006)\end{array}$ & $\begin{array}{l}-0.078^{* * *} \\
(0.010)\end{array}$ & $\begin{array}{l}-0.077 * * * \\
(0.016)\end{array}$ & $\begin{array}{l}0.049 * * * \\
(0.007)\end{array}$ & $\begin{array}{r}0.015 \\
(0.022)\end{array}$ & $\begin{array}{l}0.045^{* * *} \\
(0.009)\end{array}$ & $\begin{array}{l}0.077 * * * \\
(0.016)\end{array}$ \\
\hline Social Factor & & & & & & & & \\
\hline Social Support & $\begin{array}{r}0.001 \\
(0.004) \\
\end{array}$ & $\begin{array}{l}-0.009 * \\
(0.004)\end{array}$ & $\begin{array}{r}0.002 \\
(0.014) \\
\end{array}$ & $\begin{array}{l}-0.039 * \\
(0.016)\end{array}$ & $\begin{array}{r}-0.002 \\
(0.012) \\
\end{array}$ & $\begin{array}{c}0.036^{* * *} \\
(0.014)\end{array}$ & $\begin{array}{r}-0.001 \\
(0.006) \\
\end{array}$ & $\begin{array}{c}0.012 * \\
(0.006)\end{array}$ \\
\hline
\end{tabular}




\begin{tabular}{|c|c|c|c|c|}
\hline & \multicolumn{2}{|l|}{ Male } & \multicolumn{2}{|l|}{ Female } \\
\hline $\mathrm{N}$ & \multicolumn{2}{|c|}{743} & \multicolumn{2}{|l|}{563} \\
\hline Pseudo $\mathrm{R}^{2}$ & \multicolumn{2}{|c|}{0.149} & \multicolumn{2}{|c|}{0.129} \\
\hline LR $\chi 2$ (d.f.) & $204.61(21)$ & $* * *$ & $133.16(21)$ & $* * *$ \\
\hline
\end{tabular}

Notes: This table includes the results from two generalized ordered logistic regressions (partial proportional odds models) predicting financial satisfaction operationalized using a Likert-type scale from 1 (very dissatisfied) to 4 (very satisfied). Average marginal effects for continuous variables are reported based on one standard deviation changes in independent variables across the entire sample to standardize changes between genders. Independent variables include natural $\log$ of respondent income, natural log of spouse's income, household income share (percent of household income earned by respondent), household income adequacy (natural log of total household income divided by natural log of total household expenses), age, age squared, average hours worked per week, job satisfaction (ordinal measure on a four-point Likert-type scale from very dissatisfied to very satisfied treated as a continuous variable), a categorical variable of highest education attained (less than high school, high school, vocational or similar college, college, and graduate degree), and three factors generated via exploratory factor analysis: positive affect, negative affect, and social support. For brevity, the results from the education variable are not included (no marginal effects were significant).

$* * * p<.001, * * p<.01, * p<.05, \dagger p<.1$ 